\title{
Understanding the Sensitive Skin Subject to Achieve a More Holistic Diagnosis
}

\author{
Miranda A. Farage $\mathbb{D}$
}

check for updates

Citation: Farage, M.A.

Understanding the Sensitive Skin Subject to Achieve a More Holistic Diagnosis. Cosmetics 2021, 8, 81 . https://doi.org/10.3390/ cosmetics 8030081

Academic Editor:

Maria Pilar Vinardell

Received: 14 August 2021

Accepted: 30 August 2021

Published: 2 September 2021

Publisher's Note: MDPI stays neutral with regard to jurisdictional claims in published maps and institutional affiliations.

Copyright: (C) 2021 by the author. Licensee MDPI, Basel, Switzerland. This article is an open access article distributed under the terms and conditions of the Creative Commons Attribution (CC BY) license (https:// creativecommons.org/licenses/by/ $4.0 /)$.
The Procter and Gamble Company, Mason, OH 45040, USA; farage.m@pg.com

Abstract: Sensitive skin Syndrome (SSS) is a complex global clinical phenomenon that is defined by the self-reported presence of different sensory perceptions, including tightness, stinging, burning, tingling, pain and pruritus and often without objective signs. Due to the subjective nature of this clinical condition, the diagnosis is complex and there is often a disconnect between what subjects feel and what medical professionals can observe. This chapter reviews the known underlying physiology, some of the triggering factors associated with SSS, co-morbidities as well as the psychological impact on individuals suffering from this condition. The goal is to bridge the gap between the physicians' understanding and the subjects' perceptions of this real-life condition that affects so many.

Keywords: stress; ethnicity; gender; menstrual cycle; incontinence; genetics; dermatologic; sleep disorders; quality of life; holistic

\section{Introduction}

Sensitive Skin Syndrome (SSS) is defined as the occurrence of subjective, unpleasant sensations in response to a wide variety of external and internal stimuli that normally should not provoke such sensations [1,2]. Objective signs of skin irritation, such as redness and swelling, are not consistently present. In fact, many people who profess sensitive skin do not predictably experience visible signs of the sensations reported, whereas some who describe themselves as non-sensitive react strongly to tests of objective irritation [3]. Sensitive skin has been the subject of intense investigation in recent years, and there is an increased understanding of the underlying physiology that can lead to symptoms in individuals predisposed to this condition in response to a variety of triggering factors [4]. This chapter investigates some of the triggering factors associated with SSS, as well as the psychological impact on individuals suffering from the effects of this condition. The goal is to bridge the gap between the physicians' understanding and the subjects' perceptions of this real-life condition that affects so many.

\section{A Global Phenomenon: Prevalence of Sensitive Skin around the World}

Due to the absence of consistent objective signs investigators have relied on a questionnairebased approach to evaluate the prevalence of SSS. These have been reviewed most recently by Farage, 2019 [5]. Results of these studies vary widely from a low prevalence of about $23 \%$ to a high of over $90 \%$. The reason for these wide variations can be attributed in part to a number of differences in the manner in which the studies were conducted, including the structure of the questions, and the focus on specific anatomic sites. In addition, some investigators classified individuals as "sensitive" if they reported they had slightly, moderate, or very sensitive skin. Other investigators included only those individuals who responded they had moderate, or very sensitive skin. Chen and colleagues performed a meta-analysis on a total of 26 studies representing 18 countries and including 51,783 individuals [6]. From this pooled data they determined that the proportion of individuals with some degree of self-reported SSS (i.e., slightly, moderate, or very) was $71 \%$, and those who reported moderate or very SSS was 40\% [6].

Data on incidence from China differs from all other countries that have been surveyed. Three studies have been published on SSS in China: Farage and colleagues, and $\mathrm{Xu}$ 
and colleagues, and Wang and colleagues [7-9]. Among the surveyed populations these investigators found that only $23 \%, 40 \%$, and $24 \%$, respectively, responded they had any degree of skin sensitivity. Only $7 \%, 13 \%$, and 5\%, respectively, responded they had "very" or "moderate" skin sensitivity. It is unclear why the results from China differ so substantially from all other countries and geographies. One author suggested that it may be partially due to the fact that the term 'sensitive skin' is a relatively new term in Chinese and may not be well understood [8]. There may be other cultural influences, such as less emphasis on fashion and beauty-related advertising in China. There may also be as yet unknown genetic differences among this population.

\subsection{Sensitive Skin Is a Whole Body Phenomenon}

When thinking about sensitive skin, the main focus is typically the face [5]. The face has been demonstrated to be the most common site of skin sensitivity. This is likely related to the larger number of products used on the face (particularly in women), coupled with a thinner barrier in facial skin, and a greater density of nerve endings [10]. However, structural variations in the skin of different body sites can contribute to differences in barrier function, which may contribute to differences in skin sensitivity [11]. In addition, potential triggering factors for skin sensitivity would be expected to vary by body site. For example, the skin of the genital area is the only anatomic site other than the face where mucous membranes are exposed to the outside [12]. It is highly innervated, vascularized, and has numerous active skin appendages. Ya-Xian and colleagues investigated the thickness of the stratum corneum from various body sites and found that the smallest number of cell layers was in genital skin, followed by the skin of the face, neck, scalp, trunk, extremities, and palms and soles [13]. Measurements of TEWL were inversely proportional to the thickness of the stratum corneum. In a study of 1039 individuals in an urban area of the U.S., it was reported that $68.4 \%$ of the study population claimed some degree (slightly, moderately, or very) of skin sensitivity in general (Figure 1) [14]. When asked about specific body sites $77.3 \%$ claimed sensitive facial skin, $60.7 \%$ claimed sensitive body skin and $56.3 \%$ claimed sensitive skin in the genital area [14].

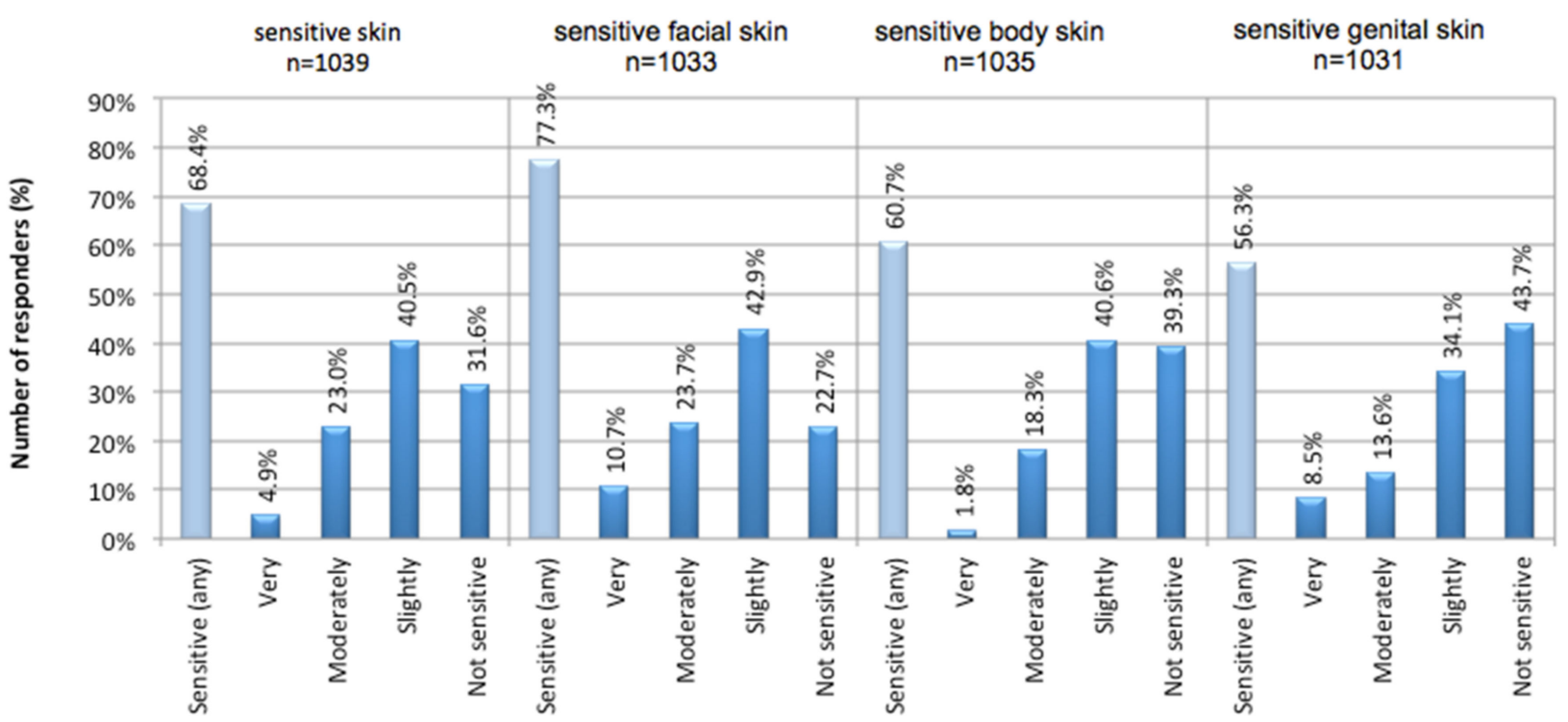

Figure 1. Prevalence of SSS. In a study conducted in the Cincinnati area among 1039 subjects, participants were asked to describe their skin and given possible responses of: not sensitive, slightly, moderately, or very sensitive. Participants were subsequently asked to use the same four-point scale to rate their skin in the following areas: facial area, body area, and genital area. The percentage of participants giving each response is plotted (adapted from [14]). 
Other investigators have evaluated different body sites that may be susceptible to SSS. Sensitive scalp is a frequent complaint [15]. In a survey of over 2000 women in England Willis and colleagues reported that $32.7 \%$ of the individuals in the group who claimed sensitive skin, in general, reported sensitive skin of the scalp compared to $13.2 \%$ of the non-sensitive group [16]. In a study conducted in France among 2117 individuals, Misery and colleagues reported $47.4 \%$ of women and $40.8 \%$ of men suffer from sensitive scalp [17]. In a study among 369 subjects in China, Ma and colleagues reported $35.77 \%$ of subjects claimed some degree of sensitivity of the scalp [15]. The hands, feet, neck, torso, back, genitals, and legs have also been investigated by a number of researchers, and all can be sites of skin sensitivity [14,18,19].

The cornea is the ocular equivalent of the epidermis, as reviewed by Misery and colleagues [20]. Many individuals experience dry eyes, sensitivity to certain cosmetics used in the eye area, intolerance to contact lenses, and other unpleasant sensations of the eyes or eyelids. Misery and colleagues conducted a survey involving 2048 subjects to evaluate a potential association between SSS and sensitive eyes and eyelids [20]. The study population consisted of $49.5 \%$ women and $50.5 \%$ men. Of the group, $52.2 \%$ declared sensitive eyes, more frequently among women $(57.2 \%$ of women and $47.3 \%$ of men; $p<0.00001)$. The number of individuals declaring sensitive eyelids was lower overall $(18.65 \%)$, with a greater proportion among women compared to men $(23.2 \%$ and $14.1 \%$, respectively; $p<0.00001)$. Multivariate analysis showed a correlation between SSS and both sensitive eyes and sensitive eyelids. The more severe the subject described his or her skin sensitivity, the more likely they were to have sensitive eyes and/or eyelids.

\subsection{Signs, Symptoms and Underlying Causes}

Individuals with SSS experience a wide variety of unpleasant sensations. Some of these are summarized in Table 1 . The specific sensations can vary from one individual to the next but generally are described as stinging, burning, pain, tingling sensations, or feelings of tightness or dryness [1,21]. This seemingly disparate set of experiences has provided important clues into the underlying causes of SS.

Table 1. Examples of unpleasant sensations experienced by individuals with SSS.

\begin{tabular}{cc}
\hline Sensation & Ref. \\
\hline Burning & {$[9,21,22]$} \\
\hline Dryness & {$[23]$} \\
\hline Itching & {$[9,21,22]$} \\
\hline Pain & {$[9,21,24]$} \\
\hline Prickling & {$[21,22]$} \\
\hline Picking & {$[21]$} \\
\hline Smarting & {$[25]$} \\
\hline Stinging & {$[24]$} \\
\hline Tickling & {$[26]$} \\
\hline Tightening & {$[9,22]$} \\
\hline Tingling & {$[9]$} \\
\hline
\end{tabular}

\subsubsection{Altered Epidermal Barrier}

A number of studies have suggested a link between SSS and disruption in barrier function [27-31]. However, attempts to quantify differences using transepidermal water loss (TEWL) have proven to be difficult [32]. Comparisons of epidermal thickness have demonstrated no significant difference between sensitive and non-sensitive individuals [33]. The permeability barrier in the stratum corneum depends on lipid composition [34]. Roussaki-Schulze and colleagues observed that individuals with SSS possess very dry skin 
with overall low fatness, which leads to a disturbance of the protective skin barrier function [35]. Decreased ceramides and sphingolipids are associated with reduced barrier integrity resulting in increased penetration of potential irritants, and inadequate protection of nerve endings $[22,32,36]$. Further, reduced barrier integrity facilitates access to antigen-presenting cells, which is consistent with an association between SSS and atopic conditions [29].

In a study reported by Chen and colleagues, the investigators evaluated three parameters in SSS subjects: the sensory response using a lactic acid sting test (LAST), barrier function using a sodium lauryl sulfate (SLS) skin irritation test, and cutaneous vascular reactivity using the reactivity to dimethyl sulfoxide (DMSO) [37]. These authors identified a subgroup of SSS individuals that exhibit the characteristics of high vascular reactivity without impaired barrier function.

Raj and colleagues evaluated 48 SSS subjects [38]. About half reacted to capsaicin. Tape strips were used to evaluate specific skin markers including: bleomycin hydrolase, or BH (proteolytic enzyme essential for epidermal integrity), pyrrolidone carboxylic acid, or PCA (hydrating agent), and transglutaminase activity, or TG (necessary for the maturation of the corneocyte envelope). All three of these markers were significantly lower in the capsaicin-sensitive subjects compared to non-capsaicin-sensitive subjects $(p<0.001,<0.001$, and $<0.0001$, respectively), indicating reduces corneocyte maturation. Further, the SC path length and the number of SC cell layers were estimated to be significantly lower in capsaicin-sensitive subjects compared with the non-capsaicin-sensitive subjects $(p<0.001)$.

\subsubsection{Neurosensory Dysfunction}

Transient receptor potential vanilloid-1 (TRPV1) is a non-selective cation channel that responds to heat and low $\mathrm{pH}$ and is related to nociception, neurogenic inflammation, and pruritus [39,40]. TRPV1 is expressed on fibroblasts, mast cells, and endothelial cells, and activation results in pain or pruritus with a burning component [40]. TRPV1 is also dramatically up-regulated by inflammatory mediators [40]. Ehnis-Pérez and colleagues obtained skin biopsies from the nasolabial fold of each of 31 subjects self-diagnosed as having SSS in order to carry out an analysis of TRPV1 [39]. Immunohistochemistry staining for TRPV1 and TRPV1 mRNA expression was greater in subjects who tested positive in the LAST. The increased mRNA expression correlated with the intensity of symptoms. The authors concluded that TRPV1 expression is up-regulated in subjects with sensitive skin. Sun et al. collected blood samples from individuals identified as having SSS via the LAST [41]. Samples were subjected to genetic analysis of four TRPV1 gene single nucleotide polymorphisms. The sensitive group was found to have a higher frequency of two specific TRPV1 genotypes compared to the non-sensitive group, indicating TRPV1 may have an important role in the pathogenesis of SSS.

Buhé and colleagues conducted a study of biopsy tissue from 50 healthy women (24 with SSS and 26 non-sensitive) [33]. They evaluated epidermal thickness, markers of skin inflammation (PAR2, TRPV-1, NFאB, ASIC-1, and GPR32), and sensory innervation via immunostainings. In this study, the investigators did not find differences in the epidermal thickness or differences in markers of inflammation. However, results indicated a difference in the intraepidermal nerve fiber density, with the SSS group having a significantly lower linear density compared to the non-sensitive group $(p=0.027)$, and a significantly lower CGRP-immunoreactive nerve fiber density $(p=0.008)$.

In the skin, unmyelinated C-fibers mediate sensations such as pain, itching, and warmth [24]. In a recent review, Misery and colleagues suggested that reduction in intraepidermal nerve fibers and alterations of $\mathrm{C}$-fibers can induce hyper-reactivity of the remaining nerve endings, contributing to both sensitive skin and small-fiber neuropathy symptoms (SFN) [42].

Querleux and colleagues used a functional MRI to evaluate brain activity during the application of lactic acid on the faces of women with and without sensitive skin [43]. These 
investigators demonstrated that sensitive skin subjects had specific cerebral activation during the test that differed from the non-sensitive controls [43].

\subsubsection{Altered Vasculature}

Increased vascular reactivity has been reported with SSS [42]. Roussaki-Schulze and colleagues were investigating SSS subjects who experienced adverse sensations in response to triggering factors without any accompanying clinical signs [35]. They subjected the skin to a number of challenges, including: LAST, patch tests with standard allergens and a cosmetic panel, methyl nicotinate application, and in vitro quantification of IgE levels. After such challenges, they evaluated a variety of biophysical and clinical parameters in SSS subjects. When reactions of the SSS subjects were compared to those of healthy volunteers without SSS, these investigators found SSS subjects had much greater vascular reactions to methyl nicotinate. Induced erythema after application of the substance was significantly greater in SSS subjects compared to non-SSS subjects $(p<0.01)$. The risk of intense vascular reaction to methyl nicotinate was 75 times higher in sensitive patients than in non-sensitive controls. In addition, the sensitive subjects had significantly greater reactions to standard allergens $(p<0.01)$ and cosmetics $(p<0.05)$. The skin of subjects with SSS also had lower hydration $(p<0.05)$, lower sebum content $(p<0.01)$, and lower alkali resistance $(p<0.05)$ [35].

Jiang and colleagues evaluated the vascular characteristics of SSS individuals using dynamic optical coherence tomography (D-OCT): a technology that can provide functional and morphologic information about the skin microvasculature in situ [44]. A total of 137 qualified volunteers aged 18 to 60 years were categorized based on a combination of a questionnaire survey, LAST results for a stinging response, and the capsaicin test positive (CATP) for a burning response. This resulted in four different groups of subjects similar in average age and gender distribution. Individuals who did not perceive they had SSS based on the questionnaire and were negative in both the LAST and CATP were identified as Group 1 (non-sensitive) $(n=39)$. The remaining groups were positive in the perception of SSS: Group $2(n=32)$ was negative in the LAST and positive in CATP $(n=32)$; Group $3(\mathrm{n}=32)$ was positive in LAST and negative in CATP; Group $4(\mathrm{n}=34)$ was positive in LAST and positive in CATP. Photographic images from the D-OCT were used to evaluate the vascular depth, shape, and density in all four groups. These investigators found that the blood vessels of individuals in the two LAST-positive groups (Groups 3 and 4) were more superficial compared to the LAST-negative groups, i.e., Group 1 (non-sensitive) $(p<0.001)$, or Group 2 (LAST-negative and CATP-positive) $(p<0.05)$. The shape of vascular patterns was significantly different in the four groups $(p=0.028)$ with a mottled shape being the most common pattern in the non-SSS individuals (Group 1), and the SSS groups (2-4) having patterns more evenly distributed between mottled, branching, and mesh. The density of blood vessels for the non-sensitive Group 1 was significantly lower $(p<0.001)$ compared to the three SSS groups (Groups 2-4) [44].

Evidence of studies into the underlying causes of SSS lead to the conclusion that this condition is not a single entity. Several investigators have proposed defining subgroups of SSS to inform personalized interventions for each individual sensitive skin patient [45]. A number of authors have proposed similar categories or SSS subgroups based on the causal pathways leading to a particular pattern of response identified by functional testing, or potential triggering factors $[2,29,45]$ These approaches have merit, however, neither approach considers the important contributions of fatigue, stress, emotion, or other psychosocial components known to contribute to SSS. A fully encompassing definition of subgroups of sensitive skin will need to account for such influences.

\section{Understanding Host Factors}

3.1. Skin Type

There are certain characteristics, or host factors, that are more likely to be seen in SSS individuals (Table 2). A higher percentage of individuals claiming sensitive skin are more 
likely to be phototypes I-IV. Misery and colleagues evaluated survey data that included 10,743 subjects from five different countries: France, China, USA, Brazil, and Russia [21]. Among the responders, $57.3 \%$ (2474 out of 4316) of individuals with skin phototype I or II claimed SSS. Among skin phototype III or IV, 42.3\% (2403 out of 5686) claimed SSS. Among skin phototype V or VI, 40.4\% claimed SSS (299 out of 741). The difference was statistically significant $(p<0.001)$. Fairer skin, susceptibility to sunburn, tendency toward blushing and flushing, and dry skin are also associated with SSS [5,21,46,47].

Table 2. Host factors associated with SSS.

\begin{tabular}{cc}
\hline Factor & Ref. \\
\hline Skin type & {$[21]$} \\
\hline Phototype I-IV & {$[5,16]$} \\
\hline Fair skin, susceptible to sunburn & {$[5,16]$} \\
\hline Susceptibility to blushing and/or flushing & {$[5,48]$} \\
\hline Skin pigmentation & {$[16,21,46,47]$} \\
\hline Dry skin & {$[14]$} \\
\hline Ethnicity ${ }^{\text {a }}$ & {$[5,9,16,21,49]$} \\
\hline Gender & {$[5,18,50]$} \\
\hline Menstrual cycle & {$[5,51,52]$} \\
\hline Age & {$[53]$} \\
\hline Incontinence & {$[21,54-56]$} \\
\hline Familial and genetic links &
\end{tabular}

In a reported study conducted in France, Misery and colleagues found that 59\% of the responders declared they had very or fairly sensitive skin $(66 \%$ of women and 51.9\% of men) [51]. Univariate analysis demonstrated that people with fair skin were almost twice as likely to report sensitive skin compared to darker skin types. Similarly, people with an atopic predisposition or individuals with dry skin were much more likely to report sensitive skin.

\subsection{Ethnicity}

In a study conducted in the US, Misery and colleagues noted that the prevalence of sensitive skin, in general, was similar among ethnic groups varying slightly from $43 \%$ for Caucasians to $52 \%$ for African-Americans, with no statistically significant difference ( $p=0.35)$ [57]. Jourdain and colleagues conducted a study among women of perceived sensitive facial skin among a population in San Francisco specifically selected to include approximately equal numbers of four ethnicities [58]. These authors found no differences between the proportions of women in the four ethnic groups who perceived they had some degree of sensitive facial skin (African-Americans, 52\%; Asians, 51\%; Euro-Americans, 50\%; and Hispanics, 54\%). In a study conducted by our group responders were asked about sensitive skin at specific body sites (Table 3) [11]. We found the perception of sensitive skin to any degree (either 'slightly', 'moderately' or 'very') was not dependent on ethnicity when subjects were asked about their skin in general, or the skin of the face or body $(p=0.15, p=0.24, p=0.13$, respectively). However, a significantly higher percentage of African-Americans perceived some degree of sensitive skin in the genital area compared to Caucasians $(p=0.012)$. 
Table 3. Ethnic differences in perceptions of sensitive skin at different body sites.

\begin{tabular}{ccccc}
\hline & General & Face & Body & Genital Area \\
\hline Caucasian $(\mathrm{n}=805)$ & $68.1 \%$ & $78.4 \%$ & $59.8 \%$ & $54.2 \%$ \\
\hline $\begin{array}{c}\text { African-American }(\mathrm{n}= \\
\text { 128) }\end{array}$ & $72.7 \%$ & $73.4 \%$ & $67.2 \%$ & $66.4 \%$ \\
\hline & $p=0.15$ & $p=0.24$ & $p=0.13$ & $p=0.012$ \\
\hline
\end{tabular}

Modified from [11,14].

\subsection{Gender}

Since SSS was first identified it has been known that women are more likely to suffer from this condition compared to men. In their meta-analysis study of worldwide data Chen and colleagues determined prevalence among women of "moderate" or "severe" sensitive skin was $45 \%$ (95\%, CI 36-55\%) and among men was 33\% (95\%, CI 24-42\%) [6]. Table 4 demonstrates the difference between genders. Two decades ago, Willis and colleagues reported the results of a study conducted in England and found a higher incidence of self-declared SSS among women compared to men (51.4\% and $38.2 \%$, respectively) [16]. This has been a consistent finding from studies conducted in most geographies. (Reviewed in [5].) In data from surveys in five countries, Misery and colleagues reported the difference between genders was statistically significant $(p<0.001)$, with $55 \%$ of women claiming sensitive skin compared to $45 \%$ of men [21]. In a survey conducted in India, Brenaut and colleagues reported significantly more women than men claimed sensitive or very sensitive skin $36.7 \%$ of women and $27.9 \%$ of men, $p<0.001$ ) [59]. Taieb and colleagues found that $22.3 \%$ of Brazilian men and $45.7 \%$ of women responded that they had rather sensitive or very sensitive skin $(p<0.001)$ [60]. In a similar study in Russia, this group reported that the prevalence was $25.4 \%$ of men and $50.1 \%$ of women $(p<0.0001)$ [60]. In a study conducted in the US among 994 subjects, $50.9 \%$ of the women and $38.2 \%$ of the men overall declared having sensitive or very sensitive skin [57]. The difference was statistically significant $(p<0.0001)$. Several other countries yielded similar findings. In a study conducted in Korea by Kim and colleagues' investigators reported a higher percentage of women claiming SSS compared to men (59.2\% and $54.4 \%$, respectively) [46]. However, in this study, the difference was not statistically significant $(p=0.187)$.

Table 4. Meta-analysis of gender differences in perceptions of SSS.

\begin{tabular}{cccccc}
\hline & $\begin{array}{c}\text { Total Number of } \\
\text { Subjects }\end{array}$ & Women & Men & Significance & Ref \\
\hline England & 2316 & $51.4 \%$ & $38.2 \%$ & NR & {$[16]$} \\
\hline $\begin{array}{c}5 \text { countries (France, } \\
\begin{array}{c}\text { China, USA, Brazil } \\
\text { and Russia) }\end{array}\end{array}$ & 10743 & $55.0 \%$ & $45.0 \%$ & $p<0.001$ & {$[21]$} \\
\hline India & 3012 & $36.7 \%$ & $27.9 \%$ & $p<0.001$ & {$[59]$} \\
\hline Brazil & 1022 & $45.7 \%$ & $22.3 \%$ & $p<0.001$ & {$[60]$} \\
\hline Russia & 1500 & $50.1 \%$ & $25.4 \%$ & $p<0.0001$ & {$[60]$} \\
\hline USA & 994 & $50.9 \%$ & $38.2 \%$ & $p<0.0001$ & {$[57]$} \\
\hline Germany & 420 & $53.9 \%$ & $36.4 \%$ & NR & {$[23]$} \\
\hline Korea & 1000 & $59.2 \%$ & $54.4 \%$ & $p=0.187$ & {$[46]$} \\
\hline China & 9154 & $15.9 \%$ & $8.6 \%$ & $p<0.001$ & {$[8]$} \\
\hline China ${ }^{\text {a }}$ & 954 & $30.0 \%$ & $20.0 \%$ & $p=0.0007$ & {$[9]$} \\
\hline Results of a meta-analysis performed & & & & \\
\hline
\end{tabular}

Results of a meta-analysis performed by Chen and colleagues [6]. Only responses of "very or "moderately" sensitive skin were considered, unless otherwise indicated. NR = Not reported. ${ }^{a}$ Slightly, fairly, or very sensitive. 


\subsection{Menstrual Cycle}

Hormonal influences are known to play a role in the overall condition of the skin $[18,50,61]$. The skin has highly sensitive receptors for estrogens in both the dermis and the epidermis [62]. As estrogen levels decrease, the skin collagen and lipid content are reduced resulting in thinner, dryer skin. Water-binding capacity is also reduced, and the barrier function of the skin is negatively impacted, resulting in reduced barrier function and elasticity [62-64]. Vasomotor function, blood circulation, and wound healing are also affected [62-64]. The fluctuating levels of female hormones can have a profound effect on the skin. In a study published in 2010 women were asked about various factors they perceived caused skin irritation [11,50]. Among women with sensitive skin $(n=518) 60 \%$ responded that the menstrual cycle caused irritation compared to $33 \%$ of the non-sensitive skin women $(n=228)$ (Table 2$)$. Falcone and colleagues reported that the majority of women with more intense perimenstrual symptoms perceived their skin as more sensitive during some phases of the menstrual cycle compared to women with lower intensity symptoms $(p=0.002)$ [18]. However, there appears to be no difference in the prevalence of SSS between pre- and post-menopausal women [65].

In data from a survey across five countries, Misery reported that women using some forms of contraception were more likely to report SSS compared to those not using contraception $(p<0.001)$ [21]. In addition, women who were pregnant or who experienced painful menstruations were more likely to report SSS [21].

\subsection{Age}

As an individual ages, the skin becomes thinner, drier, and replaces itself more slowly [52]. The skin of the elderly is also characterized by an increase in permeability but a reduction in elasticity, tensile strength, cellularity, and vascularization [52]. These physiological changes might lead one to conclude that older skin is more susceptible to irritant effects. However, clinical assessments suggest that susceptibility to skin irritation generally decreases with age, as does the capacity to produce visible physiological signs of cutaneous irritation [52]. Elderly subjects have also been shown to have decreased cutaneous innervation as well as sensory nerve function [66].

Several studies have shown that the prevalence of SSS is higher in younger individuals compared to older subjects. In a study reported in 2018 conducted in France among 5000 subjects, Misery and colleagues found that $59 \%$ of the responders declared they had very or fairly sensitive skin ( $66 \%$ of women and $51.9 \%$ of men), and SSS was more common in younger people [51]. In a study in China involving 23,113 individuals, Xiao and colleagues showed a steady decline in the prevalence of SSS in different age groups from $65.8 \%$ in the $21-30$ age group to $29.3 \%$ in the $71-80$ age group [67]. A study conducted in Korea showed a similar pattern, with a decrease in the prevalence of sensitive skin from $64.8 \%$ in individuals aged $15-29$, to $48.7 \%$ in individuals $\geq 60$ [46]. In contrast, a study conducted in the US by Misery and colleagues among 1000 subjects found no correlation between age and prevalence of SSS [57]. A 2010 publication evaluated SSS at different body sites among 1039 individuals in the US (Table 5) [52]. There was no consistent pattern with age when responders were asked about sensitive skin in general, or of the face or body, specifically. However, sensitive skin of the genital area showed an increase from $53 \%$ in subjects $\leq 30$ to $66 \%$ in subjects $\geq 50$.

Children also suffer from SSS. Misery and colleagues reported a study conducted among 608 mothers with at least one child under the age of 6 years [68]. These investigators found the prevalence of "very sensitive" or "sensitive skin" was $58.2 \%$ of girls and $48.7 \%$ of boys. 
Table 5. Perceptions of skin sensitivity among different age groups.

\begin{tabular}{|c|c|c|c|c|}
\hline & \multirow{2}{*}{$\begin{array}{l}\text { Sensitive Skin } \\
\text { in General }\end{array}$} & \multicolumn{3}{|c|}{ Sensitive Skin of Specific Sites } \\
\hline & & Face & Body & Genital Area \\
\hline \multicolumn{5}{|l|}{$<30(\mathrm{~N}=291)$} \\
\hline Sensitive (any degree) & $67.4 \%$ & $76.6 \%$ & $57.4 \%$ & $53.3 \% \mathrm{~d}$ \\
\hline Not sensitive & $32.6 \%$ & $23.4 \%$ & $42.6 \%$ & $46.7 \%$ \\
\hline \multicolumn{5}{|l|}{$31-39(\mathrm{~N}=491)$} \\
\hline Sensitive (any degree) & $69.5 \%$ & $78.4 \% \mathrm{~b}$ & $62.10 \%$ & $55.0 \% \mathrm{e}$ \\
\hline Not sensitive & $30.5 \%$ & $21.6 \%$ & $37.9 \%$ & $45.0 \%$ \\
\hline \multicolumn{5}{|l|}{$40-49(N=127)$} \\
\hline Sensitive (any degree) & $61.4 \%$ a & $69.3 \% \mathrm{c}$ & $57.5 \%$ & $58.3 \%$ \\
\hline Not sensitive & $38.6 \%$ & $30.7 \%$ & $42.5 \%$ & $41.7 \%$ \\
\hline \multicolumn{5}{|l|}{$>50(\mathrm{~N}=101)$} \\
\hline Sensitive (any degree) & $74.3 \%$ & $83.2 \%$ & $64.4 \%$ & $66.3 \%$ \\
\hline Not sensitive & $25.7 \%$ & $16.8 \%$ & $35.6 \%$ & $33.7 \%$ \\
\hline Age vs. sensitive skin & $p=0.65$ & $p=0.52$ & $p=0.28$ & $p=0.012$ \\
\hline
\end{tabular}

In a study of 1039 individuals in an urban area in the US, participants were asked if they had sensitive skin in general, and/or at specific body sites. Responders in each age group that declared any degree of sensitivity ("very", "moderate", or "slight") were included in the sensitive group (modified from [52]). Correlations between perceptions of sensitive skin and age were assessed by MH chi-square. Paired age-group comparisons were performed by chi-square analysis. $\mathrm{a}=$ Significantly lower than $>50$ group $(p=0.04) ; \mathrm{b}=$ Significantly higher than $40-49$ age group $(p=0.031) ; \mathrm{c}=$ Significantly lower than $>50$ group $(p=0.016) ; \mathrm{d}=$ Significantly lower than $>50$ group $(p=0.022)$ $\mathrm{e}=$ Significantly lower than $>50$ group $(p=0.036)$

\subsection{Impact of Incontinence}

Urinary incontinence is extremely common among women [53]. In a study conducted in Sweden among 3071 women, Hagglund and colleagues reported an overall prevalence of $26 \%$, with a prevalence of $12 \%$ among women under 30 years of age [69]. In 1988, Jolleys reported an overall prevalence of urinary incontinence of $41 \%$ in a survey among 833 women in the UK [70]. Thomas and colleagues reported that $16.6 \%$ of women reported occasional incontinence, and $8.5 \%$ reported regular incontinence in a survey of 9323 women in the London area [71].

In a survey study to evaluate the prevalence of SSS among women with incontinence, responses of 29 women with light urinary incontinence were compared to responses of 42 women with no history of incontinence [11,53]. Women with incontinence were more likely to describe their skin in general as very or moderately sensitive compared to the control group ( $p=0.008)$, however, there were no significant differences in the perception of skin at specific body sites, i.e., the body, the face and, surprisingly, the genital area. Further, there were no significant differences in environmental factors or personal care and household products perceived to trigger SSS.

An investigational study was conducted by Trowbridge and colleagues among 122 women suffering from frequent urinary incontinence to evaluate the impact of protective underwear with odor neutralizing technology on objective and subjective assessments of skin irritation [65]. Data were collected on skin sensitivity, diabetic status, and menopausal status prior to the start of the study, and after 7 and 14 days of product use. Skin sensitivity was evaluated via a questionnaire. In addition, erythema and TEWL were assessed on several sites in the genital area. When the entire test group was considered, individuals who perceived their genital skin as sensitive generally had higher erythema and TEWL scores in the genital area compared to those who did not perceive their skin as sensitive. However, the differences did not reach significance. Similar results were obtained when SSS diabetic subjects were compared to non-SSS diabetics. When the group was subdivided into premenopausal and post-menopausal, individuals with SSS in the 
post-menopausal group had significantly higher TEWL scores at the buttock $(p=0.01)$ and labia majora $(p=0.03)$ sites on Day 7 , and at the buttock $(p=0.01)$ and inner thigh control sites $(p=0.04)$ on Day 14 compared to the non-SSS post-menopausal subjects [65]. The authors concluded that skin sensitivity was associated with numerically higher (i.e., worse) erythema and TEWL scores, some reaching statistical significance. Further, sensitive skin consumers were more likely to experience irritation from products used in the genital area, to avoid certain ingredients, and to look for sensitive skin claims.

\subsection{Familial and Genetic Links}

In a study conducted in the US among 1039 individuals by Farage, subjects were asked if they had a family history of SSS [54]. Of the 711 subjects who claimed some degree of sensitive skin ("very", "sensitive", or "slightly'), 479 (63\%) responded positively to having a family history. In contrast, of the 328 subjects who answered that their skin was not sensitive, 121 (37\%) claimed a family history of SSS (Figure 2a). This difference was significant $(p<0.0001)$. A family history of SSS increased the risk of experiencing SSS by over 3-fold (odds ratio, or OR = 3.5) [54]. When asked which family member(s) also had sensitive skin, the most common response was a child for both the SSS and the non-sensitive subjects (Figure $2 b$ ).

2a. Family history for SSS and nonsensitive subjects

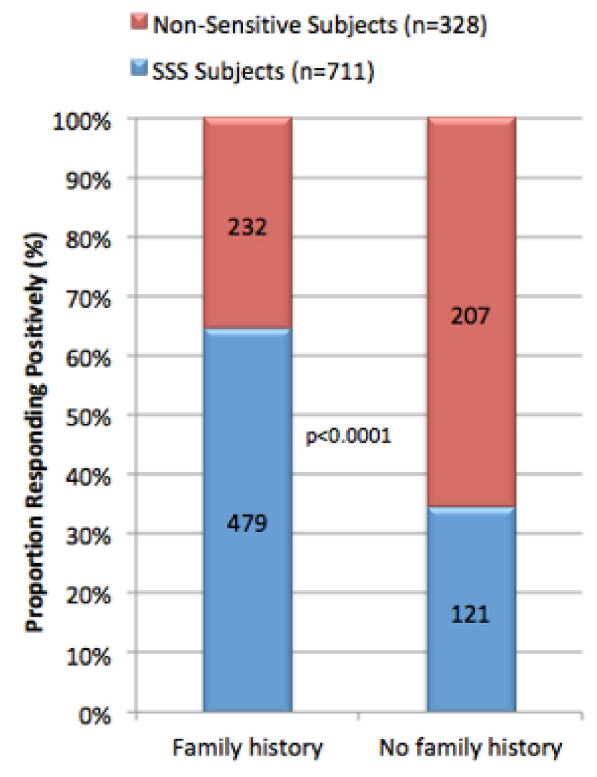

2b. Family Member with SSS

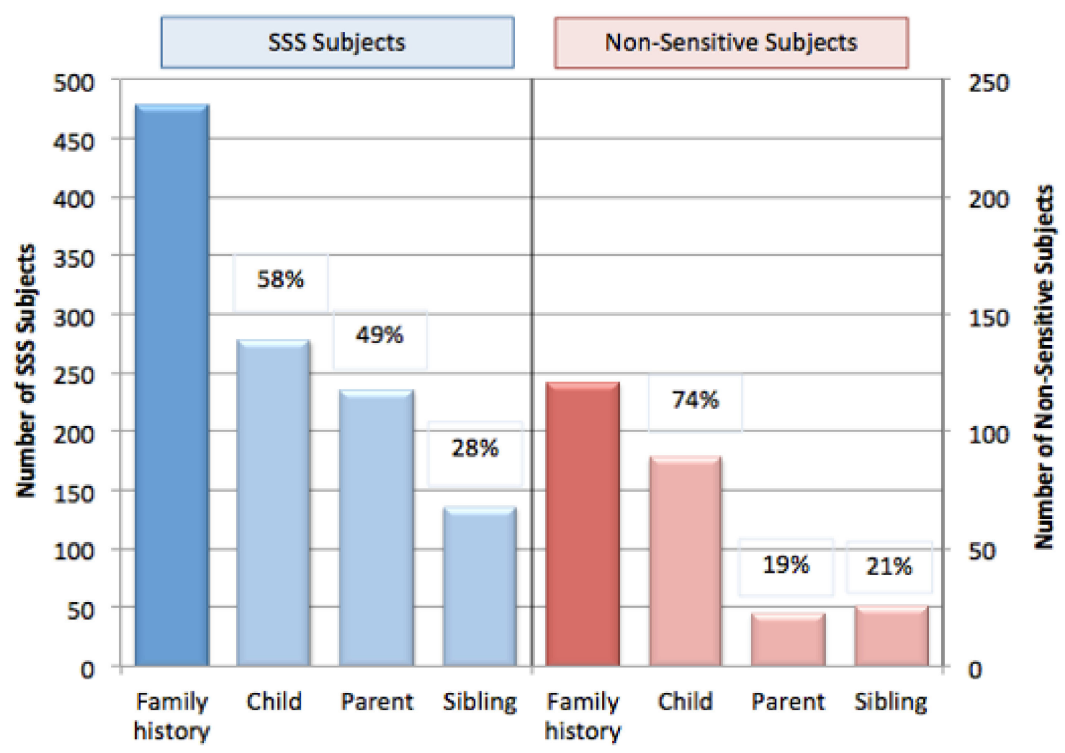

Figure 2. Family history and SSS. (a) In the Cincinnati study, 711 individuals claimed some degree of skin sensitivity (very, sensitive, or slightly), and 328 responded that their skin was not sensitive [54]. When asked if they had a family history of skin sensitivity, $63 \%$ of the SSS group (479/711) responded positively compared to $37 \%$ of the non-sensitive group (121/207). This difference was significant $(p<0.0001)$. (b) When asked which family member(s) also had SSS, the most common response was a child for both the SSS and the non-sensitive subjects.

In the study mentioned earlier on the prevalence of SSS among children by Misery and colleagues, statistical analysis revealed that if the mother had SSS, the child had an increased risk of experiencing SSS of over 3-fold $(\mathrm{OR}=3.5)$ [68]. This study suggests a familial component to SSS.

The role of genetics in sensitive skin is beginning to be explored. In a study conducted in the US, we evaluated responses to a questionnaire on SSS among 23,426 participants [55]. A genome-wide association study (GWAS) identified three loci that were significantly associated with SSS $\left(p<5 \times 10^{-8}\right)$. One locus was on chromosome 6 (variant, rs12203592) 
in the interferon regulatory factor 4 (IRF4) locus associated with skin pigmentation. A second (variant rs1805007) was in the melanocortin 1 receptor (MC1R) gene associated with several skin-related traits, including skin pigmentation, sun sensitivity, and skin cancer. The third (variant rs35407) was located in the solute carrier family 45 member 2 (SLC45A2), a gene encoding for a protein identified with melanocytes. In addition, there were seven loci with a suggested association $\left(p<1 \times 10^{-6}\right)$ to genes known to be important in skin pigmentation architecture.

Kim and colleagues evaluated the transcriptome of individuals with and without SSS [72]. These authors found that in SSS subjects' groups of genes involved in pain-related transcripts such as TRPV1, ASIC3, and CGRP were up-regulated, and a group of genes involved in muscle contraction, ion transport, and carbohydrate and lipid metabolism were down-regulated [72]. In a study of TRPV1 expression in SSS subjects, Ehnis-Pérez and colleagues demonstrated that up-regulation of TRPV1 expression correlated with the intensity of the symptoms suggesting a role for this receptor in the pathogenesis of SSS [39].

A study conducted by Yang and colleagues used RNA-sequencing assays to compare samples from a small number of SSS and non-sensitive individuals [73]. In the SSS group, Yang and colleagues identified 6750 annotated long non-coding RNAs (lnc-RNAs), and 266 novel lnc-RNAs. Long non-coding RNAs are a class of RNA sequences more than 200 nucleotides in length. They do not possess protein-coding potential but are involved in the regulation of the translation process. Long non-coding RNAs are involved in the regulation of developmental processes and in the progression of several human diseases including complex congenital syndromes, neurobehavioral and developmental disorders, and cancer $[56,74]$.

\section{Understanding the Triggering Factors for Sensitive Skin}

\subsection{Environmental, Lifestyle, Stress}

A wide variety of external factors have been identified as having the potential to trigger skin sensitivity (Table 6). In a study reported by Farage in 2008 among 1039 individuals in an urban area of the US, participants were asked if certain environmental factors triggered SSS symptoms. Extremes of humidity (wet air or dry air), extremes of temperature (hot or cold), sun, and wind were identified [75]. For all factors, the proportion of SSS individuals who responded positively was significantly different from the number of non-sensitive individuals $(p<0.0005)$. Misery and colleagues reported similar results on climatic factors. Their studies included air conditioning, variations in temperature, exposure to water, air pollution, or dust [21,57].

Brenaut and colleagues performed a meta-analysis of studies in which subjects were asked about potential triggers included in more than one survey [76]. The analysis included 13 studies conducted with over 12,000 subjects who claimed sensitive or very sensitive skin. For those potential triggers included in more than one survey, these investigators determined an odds ratio (OR). This analysis revealed that individuals with SSS were roughly 2-3 times more likely to have unpleasant sensations triggered by environmental conditions compared to individuals without sensitive skin.

Several aspects of an individual's lifestyle and habits have also been associated with triggering SSS symptoms. Wearing rough fabrics that can cause friction with the skin was identified as a trigger by $71 \%$ of SSS individuals $(470 / 711)$ compared to $43 \%$ of nonsensitive individuals (43/328) (Table 6) [75]. The difference was statistically significant $(p<0.0005)$. The use of cosmetics was clearly identified. The meta-analysis by Brenaut and colleagues revealed that individuals with SSS were over seven times more likely to have unpleasant sensations triggered by cosmetics compared to individuals without sensitive skin. In a study conducted by Misery and colleagues among 10,743 from five different geographic areas, fatigue was much more likely to be reported as a triggering factor among SSS individuals compared to non-sensitive individuals (65\% compared to 34\%, $p<0.001$ ) [21]. Xiao and colleagues found a similar result in a study involving 22,085 women in China [77]. Food and tobacco smoke were also identified by some individuals [21]. 
Table 6. Reported triggers of SSS.

\begin{tabular}{|c|c|c|c|c|}
\hline & SSS Subjects & Non-Sensitive Subjects & $p$ Value & Ref \\
\hline \multicolumn{5}{|l|}{ Environmental } \\
\hline Humid Weather ${ }^{\text {a }}$ & $48 \%$ & $13 \%$ & $<0.0005$ & [75] \\
\hline Dry weather ${ }^{a}$ & $78 \%$ & $54 \%$ & $<0.0005$ & [75] \\
\hline Hot weather ${ }^{\text {a }}$ & $66 \%$ & $32 \%$ & $<0.0005$ & [75] \\
\hline Cold weather ${ }^{a}$ & $87 \%$ & $70 \%$ & $<0.0005$ & {$[75]$} \\
\hline Sun $^{a}$ & $82 \%$ & $66 \%$ & $<0.0005$ & [75] \\
\hline Wind $^{a}$ & $71 \%$ & $53 \%$ & $<0.0005$ & {$[75]$} \\
\hline Air conditioning ${ }^{b}$ & $13 \%$ & $5 \%$ & $<0.001$ & [57] \\
\hline Temperature variation ${ }^{b}$ & $47 \%$ & $19 \%$ & $<0.001$ & [57] \\
\hline Water $^{b}$ & $15 \%$ & $6 \%$ & $<0.001$ & [57] \\
\hline Pollution ${ }^{b}$ & $63 \%$ & $33 \%$ & $<0.001$ & {$[21]$} \\
\hline Dust $^{b}$ & $58 \%$ & $29 \%$ & $<0.001$ & [21] \\
\hline \multicolumn{5}{|l|}{ Lifestyle and habits } \\
\hline Rough fabrics $^{a}$ & $71 \%$ & $43 \%$ & $<0.0005$ & [75] \\
\hline Cosmetics $^{b}$ & $58 \%$ & $22 \%$ & $<0.001$ & [57] \\
\hline Fatigue/lack of sleep ${ }^{b}$ & $65 \%$ & $34 \%$ & $<0.001$ & [21] \\
\hline Sweating $^{\mathrm{b}}$ & $54 \%$ & $27 \%$ & $<0.001$ & [21] \\
\hline Tobacco smoke $^{b}$ & $40 \%$ & $20 \%$ & $<0.001$ & {$[21]$} \\
\hline Food $^{b}$ & $44 \%$ & $17 \%$ & $<0.001$ & {$[21]$} \\
\hline \multicolumn{5}{|l|}{$\begin{array}{l}\text { Psychological and } \\
\text { physiological factors }\end{array}$} \\
\hline Stress $^{a}$ & $63 \%$ & $24 \%$ & $<0.0005$ & {$[75]$} \\
\hline Emotion $^{b}$ & $53 \%$ & $47 \%$ & $<0.001$ & [57] \\
\hline Menstrual cycle ${ }^{a, c}$ & $60 \%$ & $33 \%$ & $<0.0005$ & [50] \\
\hline
\end{tabular}

Potential triggers of SSS symptoms were included from a number of sources, as indicated. Statistical analyses compared individuals with

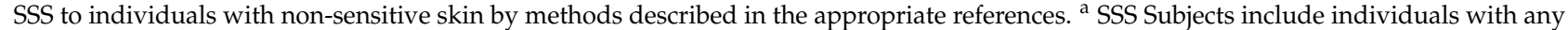
degree of sensitivity (very, moderate, slight). ${ }^{b}$ SSS Subjects include only individuals with very or moderate sensitivity. ${ }^{c}$ Women only.

Psychological factors can also trigger sensitive skin responses. In the study reported by Farage, stress was identified as a contributing factor to skin irritation by $51 \%$ of the total responding subjects (485/954). Among those subjects with some degree of perceived skin sensitivity stress was perceived as a contributor by $63 \%(415 / 654)$, compared to $24 \%$ $(70 / 290)$ of the subjects without SSS $(p<0.0005)$ [75]. In a study conducted in the US among women in Mississippi, Farage and colleagues determined that $69 \%$ of responders $(55 / 80)$ identified stress as a contributing factor [78]. Saint-Martory and colleagues reported a similar result among 400 women in France, where approximately $61 \%$ of the participants who perceived sensitive skin of the face identified stress as a contributing factor [19].

Kluger and colleagues evaluated the potential effects of containment during the 2020-2021 COVID-19 pandemic and its effects on skin conditions [79]. The study was an e-mail survey conducted among subjects in five countries (Brazil, China, France, Russia, and the US), and included 11,100 individuals. Among these individuals 64.6\% (7170 out of a total of 11,100$)$ reported they complied with containment procedures. Subjects were then divided into a SSS group including 3410 individuals (47.6\%) who responded they had sensitive or very sensitive facial skin, and a non-sensitive group including 3760 individuals (52.4\%) who had skin that was not very sensitive or not sensitive at all. Overall, among those who complied with containment procedures, $20.9 \%$ (1500 out of 7170 ) responded that their skin condition had worsened due to containment. The three main reported changes were drier skin (44.5\%), skin rash $(29.3 \%)$, and greasier skin $(27 \%)$. The investigators proposed that the wearing of masks and stress may have contributed to changes in skin conditions. 


\subsection{Impact of Everyday Products}

Our group explored specific categories of facial products and cosmetics in the study involving 1039 individuals (711 with SSS and 328 without skin sensitivity) $[75,80]$. Results shown in Figure 3 indicate that, in addition to facial and eye cosmetics, other facial products such as facial cleansers, moisturizers, and astringents were identified as triggering symptoms. Triggering of unpleasant skin sensations from specific types of personal care and household products was also examined in the study [80]. Figure 4 shows the resulting responses. Every category of product caused unpleasant symptoms in a significantly higher percentage of SSS individuals compared to non-sensitive individuals. Similar results for facial products, cosmetics, personal care, and household products were observed in a smaller study conducted in mostly rural Mississippi among a smaller number of subjects ( $n=89$, data not shown) [78]. Recognition of the needs of individuals with SSS and the large number of product categories that can trigger unpleasant sensations has resulted in an increasing emphasis by consumer product companies to develop products specifically formulated for sensitive skin.

The skin of the genital area is unique in structure compared to skin at other body sites. It has the thinnest stratum corneum of any body site that has been measured [13]. It is highly innervated and vascularized, and it is the only anatomic site other than the face where mucous membranes can be exposed to the external environment [12]. Further, the prevalence of sensitive skin of the genital area is the only body site that has been shown to increase in older individuals [52]. We were interested in products used in the genital area and their ability to trigger the unpleasant sensations associated with SSS (Figure 5). Every category of product used in the genital area caused unpleasant symptoms in a significantly higher percentage of individuals claiming genital sensitivity compared to non-sensitive individuals [11,52].

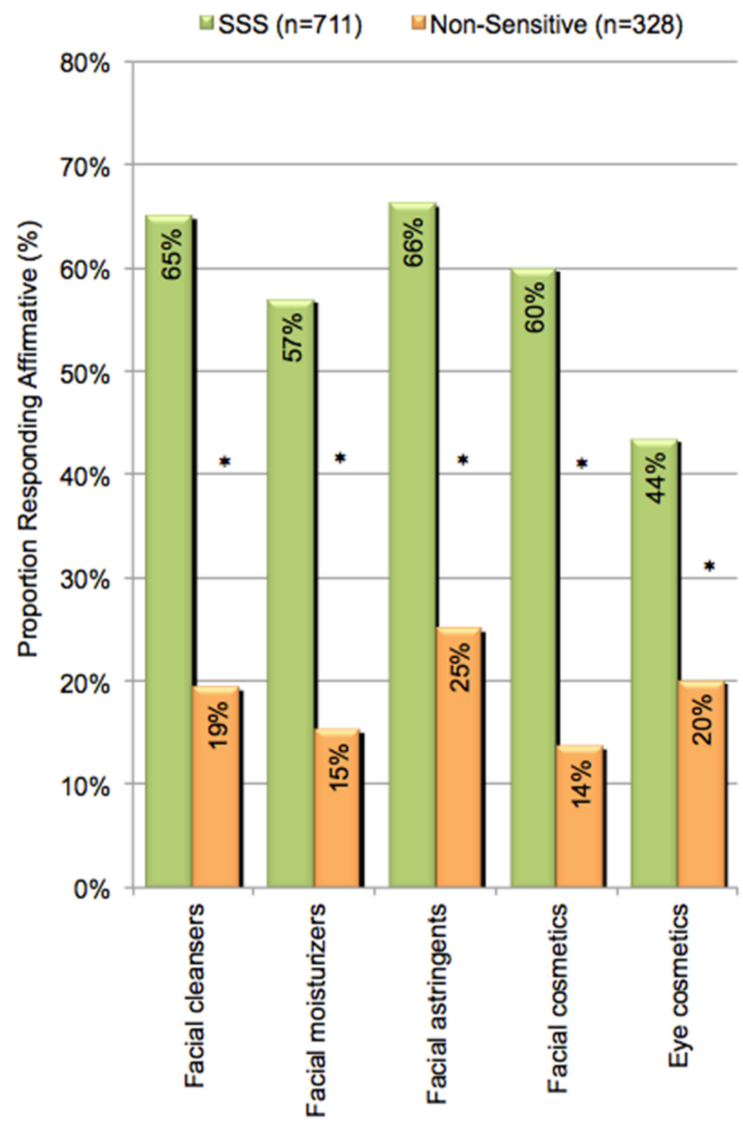

Figure 3. Facial product triggers for SSS symptoms. In the Cincinnati study, responders were asked if certain environmental factors triggered SSS symptoms [7,80]. For all factors the proportion of SSS individuals who responded positively was significantly higher than the number of non-sensitive individuals who responded positively. $\left({ }^{*}=p<0.00001\right)$. 


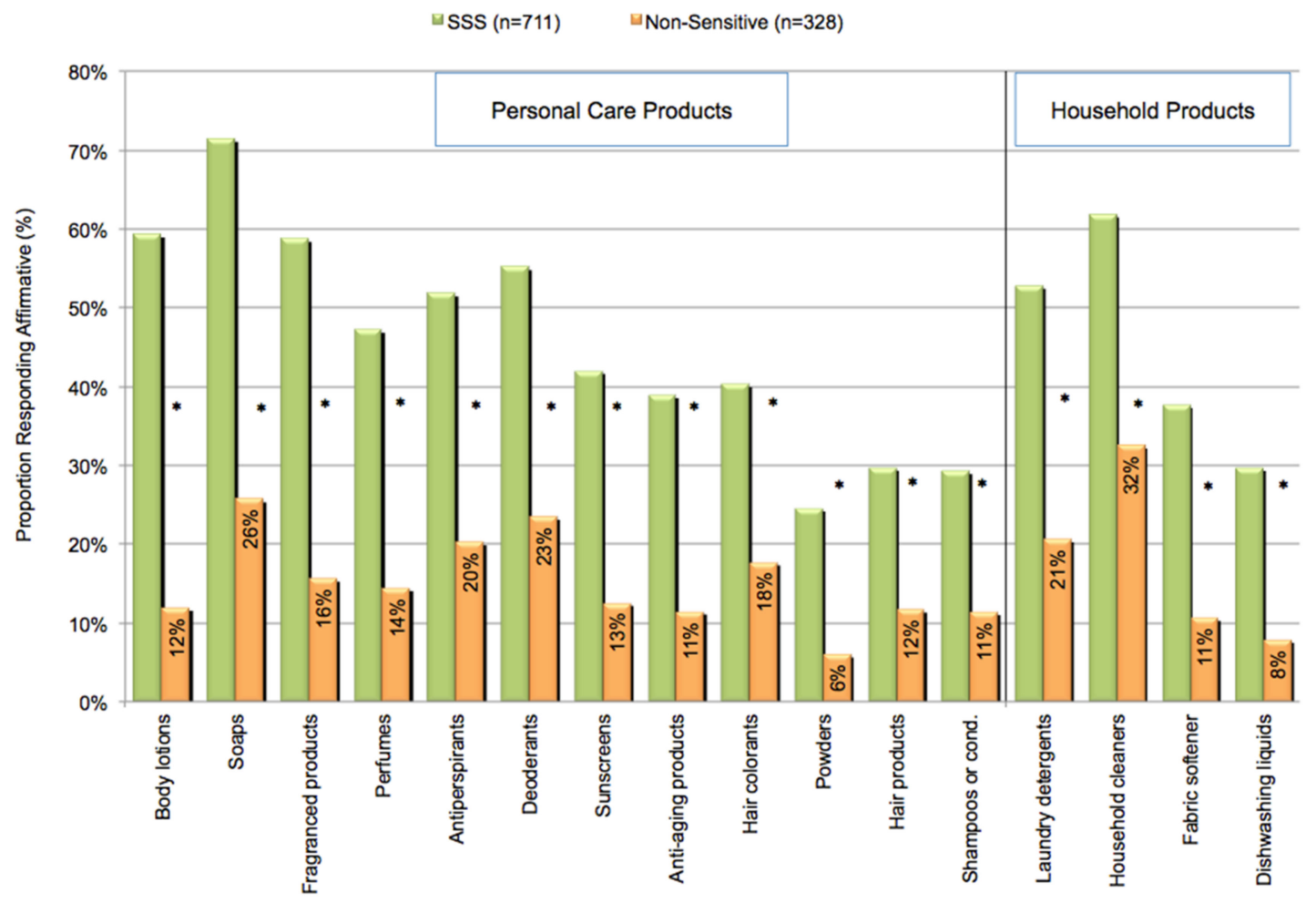

Figure 4. Household and personal care product categories reported to trigger SSS symptoms. Responders in the Cincinnati study were asked if a variety of categories of household and personal care products had ever caused adverse reactions to their skin $[7,80]$. For all product categories, the proportion of SSS individuals who responded positively was significantly higher than the number of non-SSS individuals who responded positively. $\left({ }^{*}=p<0.00001\right)$.

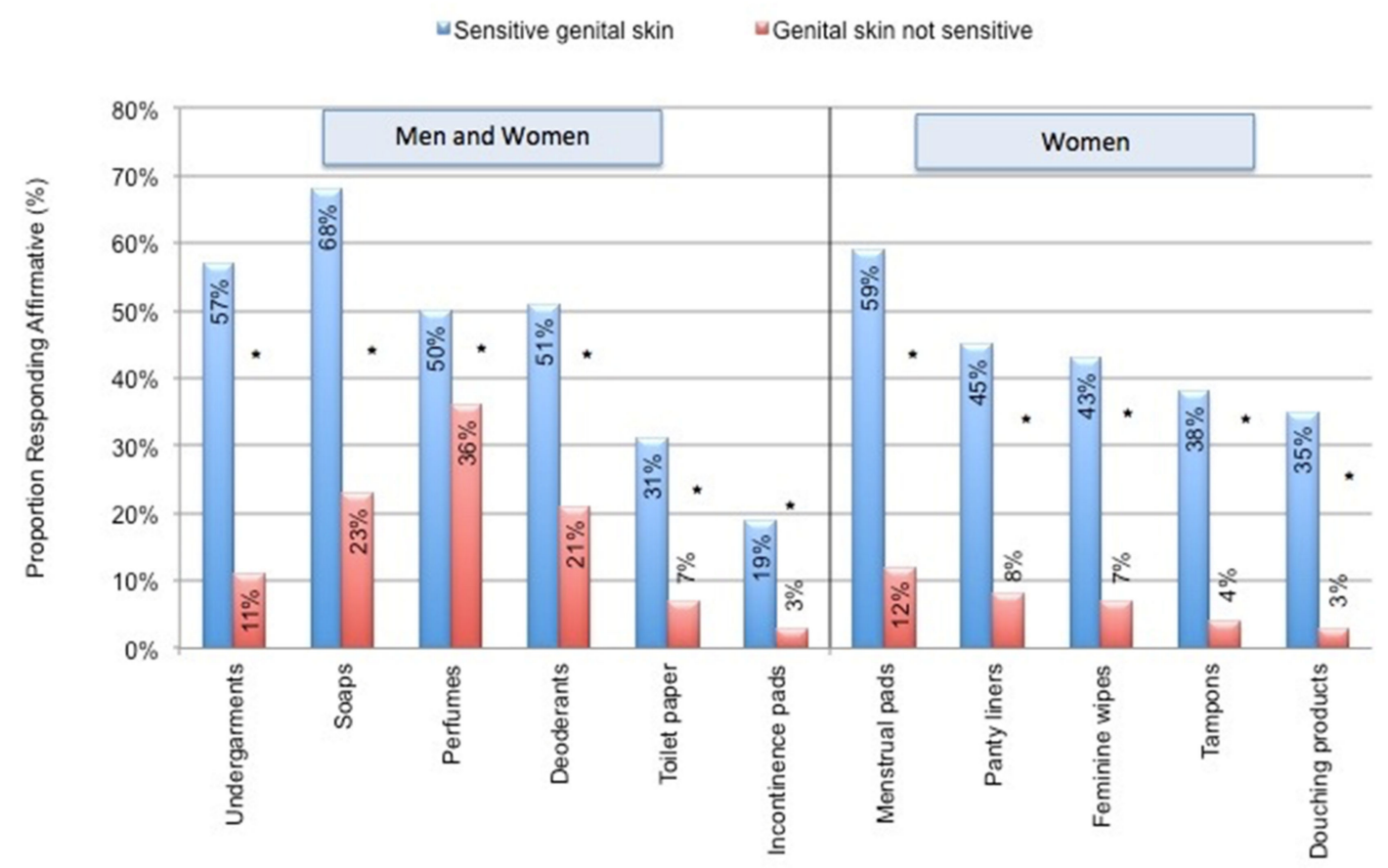

Figure 5. Products used in the genital area reported to trigger SSS symptoms. Responders in the Cincinnati study were asked if they had some degree of genital sensitivity, and whether or not specific categories of products used in the genital area triggered the unpleasant sensations of SSS at that body site (adapted from [81]). Out of the 1039 test population, 577 declared some degree of sensitive genital skin. Among the 869 women in the study, 505 declared some degree of sensitive genital skin. $(*=p<0.00001)$. 


\section{Holistic Evaluation: Other Conditions Associated with Sensitive Skin}

\subsection{Dermatologic}

Individuals with SSS are more likely to suffer from other skin disorders (Table 7). In a study involving 1000 individuals in Korea, 56.8\% of whom were had sensitive or very sensitive skin, Kim and colleagues found that the SSS group were over three times more likely to suffer from acne, atopic dermatitis, and facial blushing, and over two times more likely to suffer from seborrheic dermatitis compared to the non-sensitive group [46]. Brenaut and colleagues found a similar result in an Indian population [59]. In a study involving over 3000 individuals, SSS subjects were 2-4 times more likely to report atopic dermatitis, acne, psoriasis, vitiligo, rosacea, or contact dermatitis compared to the nonsensitive group [59]. As part of a genome-wide association study (GWAS) Farage and colleagues evaluated responses to a questionnaire administered to 23,426 individuals [55]. In this study, individuals with SSS reported other skin complaints, specifically, contact dermatitis, acne, freckles, atopic dermatitis, and seborrheic dermatitis.

Table 7. Reported skin Conditions and diseases reported by individuals with SSS.

\begin{tabular}{cc}
\hline Skin Conditions & References \\
\hline Contact dermatitis & {$[55]$} \\
\hline Atopic & {$[16,51,82]$} \\
\hline Sensitivity of the corneas and eyelids & {$[20]$} \\
\hline Rosacea & {$[59,83,84]$} \\
\hline Acne & {$[46,59]$} \\
\hline Atopic dermatitis (eczema) & {$[5,46,59]$} \\
\hline Seborrheic dermatitis (dandruff) & {$[46,59]$} \\
\hline Sensitive corneas and eyelids & {$[20]$} \\
\hline Other associations with SSS & {$[85]$} \\
\hline Irritable Bowel & {$[21,86]$} \\
\hline Sleep disorders & {$[2,4,19,78]$} \\
\hline Stress & {$[18,62]$} \\
\hline Menstrual cycle &
\end{tabular}

Rosacea is more common in individuals who are also more likely to have SSS, i.e. females with fair skin and hair, blue eyes, and skin phototypes I-III [83]. In a genome-wide association study (GWAS) involving 22,952 individuals, Chang and colleagues determined that rosacea is associated with several HLA alleles [87]. This is consistent with the inflammatory nature of the disease. In the GWAS study mentioned above, Farage and colleagues found an association between SSS and several specific loci also associated with genes for pigmentation, skin cancer, and rosacea [55].

\subsection{Non-Dermatologic}

Misery and colleagues observed that alterations of the peripheral nervous system may lead to a lowering of perception thresholds and may result in a variety of different painful conditions [20]. This has led to investigations of conditions that are not dermatologic, but where pain or other unpleasant sensations are an essential part of the disorder.

\subsubsection{Irritable Bowel Syndrome}

Unpleasant sensations of abdominal pain or discomfort are key characteristics of irritable bowel syndrome (IBS) [88]. Similarly, unpleasant sensations (stinging, burning, pain, pruritus, and tingling sensations) in response to stimuli that normally should not provoke such sensations are the hallmark of SSS [1]. In a study of 5000 individuals $(51.1 \%$ women and 
$48.9 \%$ men) representing a cross-section of the French population, Misery and colleagues developed a questionnaire regarding SSS and IBS [85]. Among the participants, $14.6 \%$ presented with IBS (17.5\% of women vs. $11.6 \%$ of men, $p<0.001)$, and $59.1 \%$ declared they had very sensitive or fairly sensitive skin $(66.0 \%$ of women vs. $51.9 \%$ of men, $p<0.001)$. Among the individuals with IBS, $73.1 \%$ also declared SSS versus only $52.3 \%$ of people without IBS $(p<0.001)$. Further, the severity and frequency of IBS increased as the severity of SSS increased $(p<0.001)$. Studies reviewed by Misery and colleagues demonstrate that both conditions may involve increased pain sensitivity and are related to alterations of the nerve endings in the peripheral nervous system and, therefore, share some common mechanisms [42,85].

A feature common to disorders in which the subject experiences unpleasant sensations in response to stimuli that normally should not provoke such sensations may be defined as a state of hyper-excitement of the central nervous system due to an amplification of neural signaling involving various synaptic and neurotransmitter activities [20]. Further, as stated by Misery and colleagues, a reduction in intra-epidermal nerve fibers and alterations of $C$ fibers, can induce hyper-reactivity of the remaining nerve endings, which can explain both sensitive skin and small-fiber neuropathy symptoms (SFN) [42].

\subsubsection{Sleep Disorders}

Halioua and colleagues found that subjects suffering from cutaneous disorders had a significantly higher severity of sleep disorders compared to control subjects without cutaneous disorders ( $4.1 \pm 2.51$ versus $3.5 \pm 2.3$, respectively, $p=0.0019)$ [86]. Pruritus and pain were good predictors of sleep disturbance with odds ratios of 1.7 [95\% CI 1.4-2.0] $(p<0.0001)$, and 1.6 [95\% CI 1.3-2.0] ( $p<0.0001)$, respectively.

Misery and colleagues conducted a survey among subjects in five different countries [21]. Participants were asked to rate the severity of sleep disorders and unpleasant skin sensations on numerical scales with 0 being no disturbance and 10 being the maximum. A score of $<3$ was considered mild, 3 to $\leq 7$ was considered moderate, and $\geq 7$ was considered severe. Among the 10,743 participants, 8296 subjects reported sleep disorders. Approximately half of these (4295 or 51.77\%) also reported SSS. Subjects with SSS had significantly higher scores for sleep disorders (3.6 out of 10) compared to subjects without sensitive skin $(1.6$ out of 10$)(p<0.001)$. The sensations experienced with SSS are similar to those experienced in SFN [89]. Sleep disorders and fatigue are common in patients with inflammatory skin disorders, such as psoriasis and chronic eczema [90], and have been reported as upstream drivers of other sensory disorders [21,91].

\subsubsection{Stress}

As discussed previously, stress is considered to be a trigger of the unpleasant sensations associated with SSS $[2,4,19,75,78]$. Stress can also trigger other dermatologic conditions such as rosacea, psoriasis, and atopic dermatitis [92-94]. However, the reverse relationship is also true. A person suffering from SSS is more likely to feel stress. Misery and colleagues evaluated Quality of Life (QoL) using the SF-12 questionnaire [95]. Individuals with sensitive or very sensitive skin had a worse QoL than individuals without. Further, the QoL deteriorated as the severity of sensitive skin increased. More recent studies have shown similar results [51,96]. As shown in Table 6, stress was reported as a trigger of unpleasant skin symptoms by $63 \%$ of the SSS subjects in the Cincinnati study involving 1039 individuals [75]. In that same study responders in each age group were asked if they had some degree of genital sensitivity, and whether or not specific environmental factors triggered the unpleasant sensations of SSS in the genital area (Table 8) [52]. Overall, 58\% of individuals with genital irritation claimed stress was a trigger. 
Table 8. Perceptions about triggers of SSS for those claiming genital skin sensitivity.

\begin{tabular}{|c|c|c|c|c|c|c|c|c|}
\hline Sensitive Skin in the Genital Area & Hot Weather & $\begin{array}{c}\text { Cold } \\
\text { Weather }\end{array}$ & Rough Fabric & $\begin{array}{c}\text { Dry } \\
\text { Weather }\end{array}$ & Stress & & $\begin{array}{l}\text { Humid } \\
\text { Weather }\end{array}$ & $\begin{array}{c}\text { Menstrual } \\
\text { Cycle }^{a}\end{array}$ \\
\hline Total sensitive responders & 546 & 553 & 551 & 548 & 548 & & 530 & 441 \\
\hline Factor causes irritation (\%) & $88 \% \quad b$ & $86 \%$ & $86 \% \quad c$ & $72 \%$ & $58 \%$ & & $47 \%$ & $30 \%$ \\
\hline \multicolumn{9}{|l|}{$\geq 50$} \\
\hline Total sensitive responders & 59 & 59 & 64 & 60 & 62 & & 60 & 23 \\
\hline Factor causes irritation (\%) & $88 \% \quad b$ & $86 \%$ & $86 \% \quad c$ & $72 \%$ & $58 \%$ & & $47 \%$ & $30 \%$ \\
\hline \multicolumn{9}{|l|}{$40-49$} \\
\hline Total sensitive responders & 68 & 70 & 70 & 67 & 68 & & 66 & 42 \\
\hline Factor causes irritation (\%) & $57 \%$ & $79 \%$ & $71 \%$ & $73 \%$ & $44 \%$ & e & $39 \%$ & $52 \%$ \\
\hline \multicolumn{9}{|l|}{$31-39$} \\
\hline Total sensitive responders & 256 & 261 & 255 & 257 & 256 & & 245 & 229 \\
\hline Factor causes irritation (\%) & $64 \%$ & $86 \%$ & $71 \%$ & $79 \%$ & $62 \%$ & & $44 \%$ & $62 \%$ \\
\hline \multicolumn{9}{|l|}{$\leq 30$} \\
\hline Total sensitive responders & 151 & 151 & 150 & 152 & 150 & & 147 & 137 \\
\hline Factor causes irritation (\%) & $59 \%$ & $82 \%$ & $75 \%$ & $76 \%$ & $65 \%$ & & $45 \%$ & $65 \%$ \\
\hline
\end{tabular}

In the Cincinnati study, responders in each age group were asked if they had some degree of genital sensitivity, and whether or not specific environmental factors triggered the unpleasant sensations of SSS in the genital area. Paired comparisons of age groups were carried out using the $\mathrm{MH}$ chi-square test. ${ }^{\mathrm{a}}$ Women only. ${ }^{\mathrm{b}} \geq 50$ age group significantly higher than $40-49,31-39$, and $\leq 30$ age groups $(p \leq 0.001)$ (adapted from [52]). ${ }^{c} \geq 50$ age group significantly higher than $40-49,31-39$, and $\leq 30$ age groups $(p \leq 0.03)$. ${ }^{\mathrm{d}} \geq 50$ age group significantly lower than $31-39$ and $\leq 30$ age groups $(p<0.02)$. ${ }^{\mathrm{e}} 40-49$ age group significantly lower than $31-39$ and $\leq 30$ age groups $(p<0.02)$.

\subsubsection{Menstrual Cycle}

The menstrual cycle can profoundly affect skin sensitivity. The skin has highly sensitive receptors for estrogens in both the dermis and the epidermis, and fluctuating levels of female hormones can have an effect on the skin [62]. Decreased estrogen levels can adversely affect barrier function, elasticity, vasomotor function, and blood circulation. The menstrual cycle was identified as contributing to unpleasant skin sensations by $60 \%$ of women with SSS and 33\% of the non-sensitive skin women (Tables 2 and 8). Falcone and colleagues reported that the majority of women with more intense perimenstrual symptoms perceived their skin as more sensitive during some phases of the menstrual cycle compared to women with lower intensity symptoms $(p=0.002)$ [18]. Further, among post-menopausal women claiming sensitive skin, over $70 \%$ perceived their skin sensitivity increased after menopause [18]. Among women with SSS, products used for menstrual protection and hygiene have been shown to trigger SSS symptoms in the genital area to a significantly greater extent than non-sensitive women (Figure 5).

\section{The Burden of SSS: How Does It Impact Daily Life?}

\subsection{Avoidance}

Individuals with SSS need to avoid a long list of triggering factors in order to minimize their symptoms. Responses to weather-related triggers listed in Table 6 can lead to a limit on various outdoor activities. In addition, a large number of everyday items, such as personal care and household products, certain foods, and certain types of fabrics, can trigger symptoms in SSS individuals. Coping with and avoiding these triggers can place a substantial emotional and physical burden on the SSS individual.

In a study reported by Farage of 1039 individuals in Cincinnati, it was reported that $68.4 \%$ of the study population claimed their skin was sensitive to some degree (slightly, moderately, or very) [14]. When asked the reason for thinking they had SSS, 50.2\% of the sensitive individuals responded it was due to adverse reactions to products (sensory or visual). When asked how their SSS influenced shopping practices, the subjects were five times more likely to look for skin-related claims on products (such as, "safe for sensitive skin" and "hypoallergenic") compared to non-sensitive subjects (OR = 5.3) (Figure 6a). 
The SSS subjects were also five times more likely to avoid specific ingredients because the individual perceived they caused skin irritation $(\mathrm{OR}=5.2)$ (Figure $6 \mathrm{~b})$.
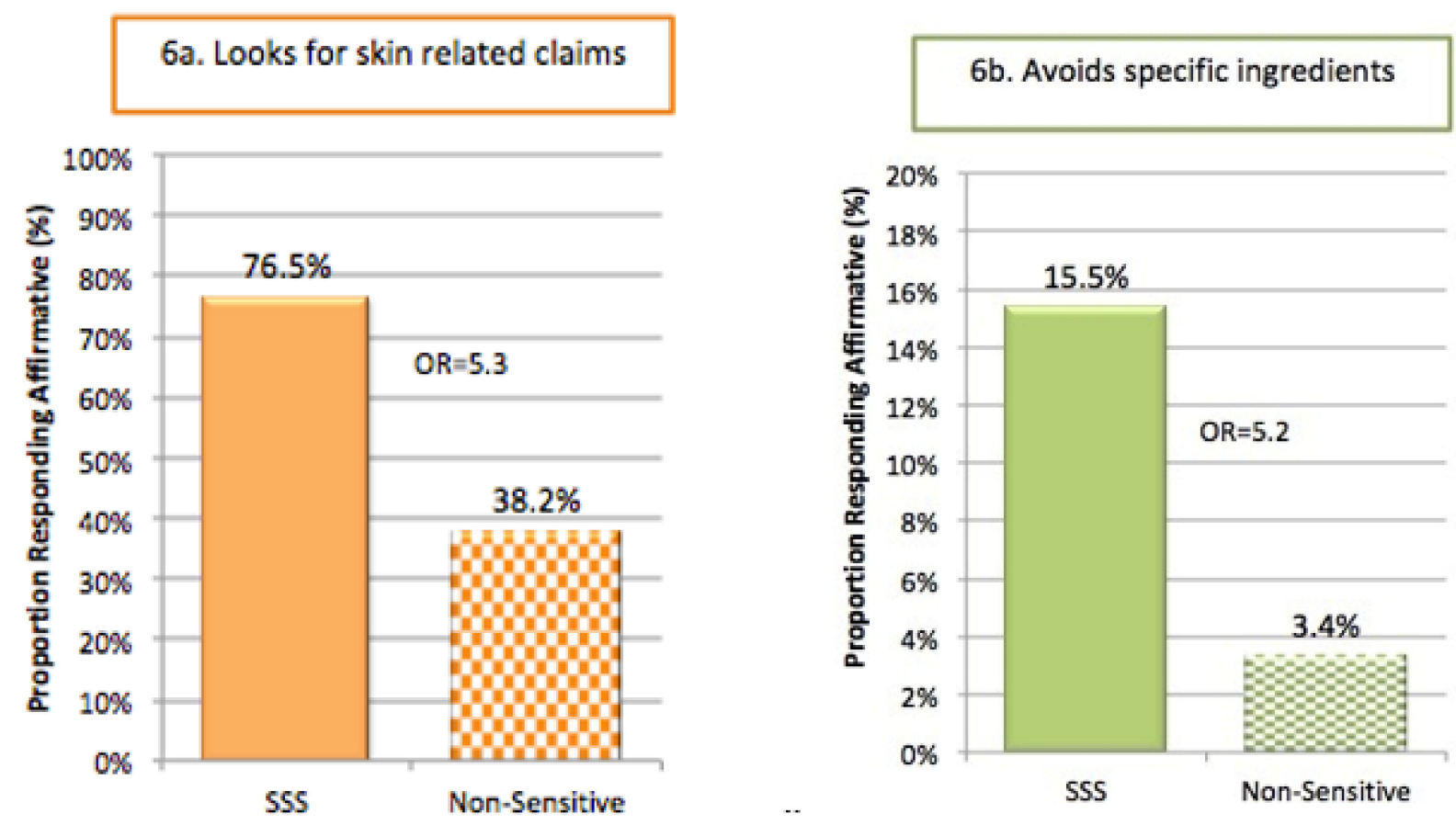

Figure 6. Influence of SSS on shopping practices. Responders in the Cincinnati study were asked about specific shopping practices. (a) Compared to the non-SS group, the SS subjects were far more likely to look for skin-related claims on products (such as, "safe for sensitive skin" and "hypoallergenic") (odds ratio (OR) = 5.3). (b) The SS group was more likely to avoid specific ingredients when shopping. (odds ratio $(\mathrm{OR})=5.2$ ).

\subsection{Quality of Life}

Several instruments have been used to evaluate the effects of SSS on the quality of life (QoL). The Dermatology Life Quality Index (DLQI) was developed by Finlay and Khan in 1994 to evaluate the impact of skin diseases in general on QoL [97]. The Short Form-12 (SF-12) has also been used as a measure of generic health status [98]. In 2018, Misery and colleagues reported on the development of a 14-item instrument, the Burden of Sensitive Skin (BoSS) questionnaire, designed specifically to determine the impact of SSS on QoL [99]. The BoSS questionnaire is composed of items grouped into three dimensions: Self-Care, Daily Life, and Appearance. The results of the questionnaire showed a good correlation with the severity of SSS declared by the test subjects. Individuals with very sensitive skin had a mean score $( \pm \mathrm{SD})$ of $23.22( \pm 12.04)$, moderately sensitive a mean of $15.36( \pm 10.59)$, and slightly sensitive a mean of $7.97( \pm 8.17)$. The BoSS had a good correlation with the DQLI, but the BoSS is focused specifically on sensitive skin rather than the broader spectrum of skin diseases. These instruments have been used in various studies over the past years to measure the impact of sensitive skin on QoL.

Two studies were conducted by Misery and colleagues on the effects of seasonal changes on SSS $[95,100]$. Skin sensitivity was evaluated using a questionnaire and classified as very sensitive, sensitive, slightly sensitive, or not sensitive. In addition, QoL was assessed using the SF-12. Two scores can be calculated from the SF-12: a Physical Component Summary (PCS-12) and a Mental Component Summary (MCS-12). The investigators evaluated PCS-12 and MCS-12 scores in light of the degree of severity declared by the SSS subjects. They found that the more sensitive the skin was, the greater the impairment of the psychological component of QoL.

Misery and colleagues conducted a study among a 5000 person sample in France [51]. Responders were classified as very, fairly, slightly, or not sensitive. These investigators 
evaluated QoL using the DLQI, and the SF-12 (with the PCS-12 and MCS-12 calculated). Based on the DLQI, the QoL for the sensitive group (i.e., very + fairly sensitive) was significantly worse than for the non-sensitive (i.e., slightly and not sensitive) $(p<0.00001)$. Similarly, the MCS-12 (i.e., mental dimension of the SF-12) was significantly worse for the sensitive group $(p<0.00001)$. The correlation was weak for the PCS-12 (i.e., physical dimension), which was consistent with earlier findings [95,100].

In the course of a clinical study evaluating the efficacy of a topical combination product on SSS, Fauger and colleagues assessed the impact of SSS on the quality of life using the DLQI [101]. The evaluation was conducted before treatment with the topical cream and after 4 weeks of treatment. As part of the clinical study, the following parameters were evaluated: stinging using the LAST; erythema after application of SLS; and burning using the CATP. The investigators saw a significant reduction in stinging scores after one application of the test product. Erythema due to the application of SLS significantly decreased $(p<0.01)$ twenty-four hours after using the test product compared to control. After 28 days of test product use, the tolerated concentration of capsaicin in the CATP increased significantly $(p<0.01)$, indicating a higher threshold to sensations of burning. The DLQI score was also improved significantly $(p<0.001)$ compared to the scores prior to the start of treatment.

Our group has developed a QoL instrument specifically to assess the impact of consumer products on QoL [102]. The conceptual model was that certain consumer products have indirect effects on the QoL of consumers beyond their direct effect on beauty, hygiene, and cleanliness. Aspects of QoL most likely to be affected include self-image, self-confidence, social function, emotion, and well-being, whereas aspects such as physical function are less likely to be impacted. The resulting 27-item questionnaire (i.e., the Farage Quality of Life, or FQoL ${ }^{\mathrm{TM}}$ general questionnaire) has been used to assess the potential impact of feminine protection products, toilet paper products, and skin conditioning lotions. The instrument was used successfully to evaluate the impact of a three-part skincare regimen on several aspects of QoL in three test groups: a national representative sample $(n=90)$ and new mothers $(n=83)$ in Australia, and young cosmetics users in China $(n=40)$ [103]. After a 28-day period of product usage, all groups showed significant improvement in several aspects of QoL including improved self-esteem, happiness, attractiveness, and the level of confidence without make-up. These promising results indicate the instrument would be valuable in evaluating the effectiveness of products specifically developed for SSS.

\section{Conclusions}

The prevalence of SSS varies in different geographies and cultures, but it is generally agreed that this condition affects a substantial portion of the population, and a wide variety of factors contribute to SSS, including host-related factors (i.e., skin type, gender, and hormonal factors), and external factors (i.e., climate, exposures to products and chemicals, and differences in habits and lifestyle). This condition has a substantial impact on the daily life of SSS individuals and often limits the activities they can pursue, and the types of everyday products they can use. For the medical practitioner, the subjective nature of SSS complicates the diagnosis, and there is often a disconnect between what subjects feel and what medical professionals can observe. This chapter attempts to bring several physical, emotional, and mental aspects of SSS into focus and explore the current understanding of the etiology of this condition, thereby raising awareness of the medical community and bridging the patients' perceptions and the physicians' understanding of this real-life condition.

Funding: This research received no external funding.

Institutional Review Board Statement: Not applicable.

Informed Consent Statement: Not applicable.

Data Availability Statement: Not applicable.

Conflicts of Interest: Author is an employee of The Procter and Gamble Company. 


\section{References}

1. Misery, L.; Ständer, S.; Szepietowski, J.C.; Reich, A.W.; Wallengren, J.; Evers, A.; Takamori, K.; Brenaut, E.; Gall-Ianotto, C.; Fluhr, J.; et al. Definition of Sensitive Skin: An Expert Position Paper from the Special Interest Group on Sensitive Skin of the International Forum for the Study of Itch. Acta Derm.-Venereol. 2017, 97, 4-6. [CrossRef]

2. Berardesca, E.; Farage, M.; Maibach, H. Sensitive skin: An overview. Int. J. Cosmet. Sci. 2013, 35, 2-8. [CrossRef]

3. Farage, M.A.; Maibach, H.I. Sensitive Skin: New Findings Yield New Insights. In Textbook of Cosmetic Dermatology; Informa Healthcare: New York, NY, USA, 2010; pp. 73-83.

4. Do, L.H.D.; Azizi, N.; Maibach, H. Sensitive Skin Syndrome: An Update. Am. J. Clin. Dermatol. 2019, 21, 401-409. [CrossRef] [PubMed]

5. Farage, M.A. The Prevalence of Sensitive Skin. Front. Med. 2019, 6, 98. [CrossRef] [PubMed]

6. Chen, W.; Dai, R.; Li, L. The prevalence of self-declared sensitive skin: A systematic review and meta-analysis. J. Eur. Acad. Dermatol. Venereol. 2019, 34, 1779-1788. [CrossRef]

7. Farage, M.A.; Mandl, C.P.; Berardesca, E.; Maibach, H.I. Sensitive Skin in China. J. Cosmet. Dermatol. Sci. Appl. $2012,2,184-195$. [CrossRef]

8. Xu, F.; Yan, S.; Wu, M.; Li, F.; Sun, Q.; Lai, W.; Shen, X.; Rahhali, N.; Taieb, C.; Xu, J. Self-declared sensitive skin in China: A community-based study in three top metropolises. J. Eur. Acad. Dermatol. Venereol. 2013, 27, 370-375. [CrossRef]

9. Wang, X.; Su, Y.; Zheng, B.; Wen, S.; Liu, D.; Ye, L.; Yan, Y.; Elias, P.M.; Yang, B.; Man, M. Gender-related characterization of sensitive skin in normal young Chinese. J. Cosmet. Dermatol. 2020, 19, 1137-1142. [CrossRef]

10. Chew, A.; Maibach, H. Sensitive Skin. In Dry Skin and Moisturizers: Chemistry and Function; Loden, M., Miabach, H., Eds.; CRC Press: Boca Raton, FL, USA, 2000; pp. 429-440.

11. Farage, M.A. Sensitive Skin in the Genital Area. Front. Med. 2019, 6, 1-18. [CrossRef] [PubMed]

12. Tagami, H. Functional characteristics of the stratum corneum in photoaged skin in comparison with those found in intrinsic aging. Arch. Dermatol. Res. 2008, 300, S1-S6. [CrossRef] [PubMed]

13. Ya-Xian, Z.; Suetake, T.; Tagami, H. Number of cell layers of the stratum corneum in normal skin-relationship to the anatomical location on the body, age, sex and physical parameters. Arch. Dermatol. Res. 1999, 291, 555-559. [CrossRef] [PubMed]

14. Farage, M.A. How do perceptions of sensitive skin differ at different anatomical sites? An epidemiological study. Clin. Exp. Dermatol. 2009, 34, e521-e530. [CrossRef] [PubMed]

15. Ma, L.; Guichard, A.; Humbert, P.; Zheng, S.; Tan, Y.; Yu, L.; Qin, O.; Wang, X. Evaluation of the severity and triggering factors of sensitive scalp in Chinese females. J. Cosmet. Dermatol. 2016, 15, 219-225. [CrossRef] [PubMed]

16. Willis, C.M.; Shaw, S.; De Lacharriere, O.; Baverel, M.; Reiche, L.; Jourdain, R.; Bastien, P.; Wilkinson, J. Sensitive skin: An epidemiological study. Br. J. Dermatol. 2001, 145, 258-263. [CrossRef] [PubMed]

17. Misery, L.; Rahhali, N.; Ambonati, M.; Black, D.; Saint-Martory, C.; Schmitt, A.-M.; Taieb, C. Evaluation of sensitive scalp severity and symptomatology by using a new score. J. Eur. Acad. Dermatol. Venereol. 2011, 25, 1295-1298. [CrossRef] [PubMed]

18. Falcone, D.; Richters, R.J.; Uzunbajakava, N.E.; Van Erp, P.E.; Van De Kerkhof, P.C. Sensitive skin and the influence of female hormone fluctuations: Results from a cross-sectional digital survey in the Dutch population. Eur. J. Dermatol. 2017, $27,42-48$. [CrossRef]

19. Saint-Martory, C.; Roguedas-Contios, A.; Sibaud, V.; Degouy, A.; Schmitt, A.; Misery, L. Sensitive skin is not limited to the face. Br. J. Dermatol. 2008, 158, 130-133. [CrossRef]

20. Misery, L.; Cochener, B.; Brenaut, E.; Seite, S.; Taieb, C. Association of sensitive skin with sensitive corneas and sensitive eyelids. J. Eur. Acad. Dermatol. Venereol. 2019, 33, 1358-1362. [CrossRef]

21. Misery, L.; Morisset, S.; Seite, S.; Brenaut, E.; Ficheux, A.; Fluhr, J.W.; Delvigne, V.; Taieb, C. Relationship between sensitive skin and sleep disorders, fatigue, dust, sweating, food, tobacco consumption or female hormonal changes: Results from a worldwide survey of 10,743 individuals. J. Eur. Acad. Dermatol. Venereol. 2021, 35, 1371-1376. [CrossRef]

22. Pons-Guiraud, A. Sensitive skin: A complex and multifactorial syndrome. J. Cosmet. Dermatol. 2004, 3, 145-148. [CrossRef]

23. Löffler, H.D.H.; Dickel, H.; Kuss, O.; Diepgen, T.L.; Effendy, I. Characteristics of Self-estimated Enhanced Skin Susceptibility. Acta Derm.-Venereol. 2001, 81, 343-346.

24. Ständer, S.; Schneider, S.W.; Weishaupt, C.; Luger, T.A.; Misery, L. Putative neuronal mechanisms of sensitive skin. Exp. Dermatol. 2009, 18, 417-423. [CrossRef] [PubMed]

25. Diogo, L.; Papoila, A.L. Is it possible to characterize objectively sensitive skin? Ski. Res. Technol. 2010, 16, 30-37. [CrossRef]

26. Löffler, H. Contact Allergy and Sensitive Skin. In Sensitive Skin Syndrome; Berardesca, E., Fluhr, J.W., Maibach, H.I., Eds.; Taylor \& Francis: New York, NY, USA, 2006; pp. 225-235.

27. Lee, C.H.; Maibach, H.I. The sodium lauryl sulfate model: An overview. Contact Dermat. 1995, 33, 1-7. [CrossRef]

28. Seidenari, S.; Francomano, M.; Mantovani, L. Baseline biophysical parameters in subjects with sensitive skin. Contact Dermat. 1998, 38, 311-315. [CrossRef]

29. Muizzuddin, N.; Marenus, K.D.; Maes, D.H. Factors defining sensitive skin and its treatment. Am. J. Contact Dermat. 1998, 9 , 170-175. [PubMed]

30. Draelos, Z.D. Sensitive skin: Perceptions, evaluation, and treatment. Am. J. Contact Dermat. 1997, 8, 67-78.

31. Effendy, I.; Loeffler, H.; Maibach, H.I. Baseline transepidermal water loss in patients with acute and healed irritant contact dermatitis. Contact Dermat. 1995, 33, 371-374. [CrossRef] [PubMed] 
32. Cho, H.J.; Chung, B.Y.; Lee, H.B.; Kim, H.O.; Park, C.W.; Lee, C.H. Quantitative study of stratum corneum ceramides contents in patients with sensitive skin. J. Dermatol. 2012, 39, 295-300. [CrossRef] [PubMed]

33. Buhé, V.; Vié, K.; Guéré, C.; Natalizio, A.; Lhéritier, C.; Gall-Ianotto, C.; Huet, F.; Talagas, M.; Lebonvallet, N.; Marcorelles, P.; et al. Pathophysiological Study of Sensitive Skin. Acta Derm.-Venereol. 2016, 96, 314-318. [CrossRef]

34. Lampe, M.A.; Burlingame, A.L.; Whitney, J.; Williams, M.L.; Brown, B.E.; Roitman, E.; Elias, P.M. Human stratum corneum lipids: Characterization and regional variations. J. Lipid Res. 1983, 24, 120-130. [CrossRef]

35. Roussaki-Schulze, A.V.; Zafiriou, E.; Nikoulis, D.; Klimi, E.; Rallis, E.; Zintzaras, E. Objective biophysical findings in patients with sensitive skin. Drugs Exp. Clin. Res. 2005, 31, 17-24.

36. Cua, A.B.; Wilhelm, K.-P.; Maibach, H. Cutaneous sodium lauryl sulphate irritation potential: Age and regional variability. Br. J. Dermatol. 1990, 123, 607-613. [CrossRef]

37. Chen, S.Y.; Yin, J.; Wang, X.M.; Liu, Y.Q.; Gao, Y.R.; Liu, X.P. A new discussion of the cutaneous vascular reactivity in sensitive skin: A sub-group of SS. Ski. Res. Technol. 2018, 24, 432-439. [CrossRef]

38. Raj, N.; Voegeli, R.; Rawlings, A.V.; Doppler, S.; Imfeld, D.; Munday, M.R.; Lane, M.E. A fundamental investigation into aspects of the physiology and biochemistry of the stratum corneum in subjects with sensitive skin. Int. J. Cosmet. Sci. 2017, 39, 2-10. [CrossRef]

39. Ehnis-Pérez, A.; Torres-Álvarez, B.; Cortés-García, D.; Hernández-Blanco, D.; Fuentes-Ahumada, C.; Castanedo-Cázares, J.P. Relationship between transient receptor potential vanilloid-1 expression and the intensity of sensitive skin symptoms. J. Cosmet. Dermatol. 2016, 15, 231-237. [CrossRef]

40. Kueper, T.; Krohn, M.; Haustedt, L.O.; Hatt, H.; Schmaus, G.; Vielhaber, G. Inhibition of TRPV1 for the treatment of sensitive skin. Exp. Dermatol. 2010, 19, 980-986. [CrossRef]

41. Sun, L.; Wang, X.; Zhang, Y.; Wang, T.; Li, X.; Ma, Y. The evaluation of neural and vascular hyper-reactivity for sensitive skin. Ski. Res. Technol. 2016, 22, 381-387. [CrossRef]

42. Misery, L.; Weisshaar, E.; Brenaut, E.; Evers, A.W.M.; Huet, F.; Ständer, S.; Reich, A.; Berardesca, E.; Serra-Baldrich, E.; Wallengren, J.; et al. Pathophysiology and management of sensitive skin: Position paper from the special interest group on sensitive skin of the International Forum for the Study of Itch (IFSI). J. Eur. Acad. Dermatol. Venereol. 2020, 34, 222-229. [CrossRef]

43. Querleux, B.; Dauchot, K.; Jourdain, R.; Bastien, P.; Bittoun, J.; Anton, J.-L.; Burnod, Y.; De Lacharrière, O. Neural basis of sensitive skin: An fMRI study. Ski. Res. Technol. 2008, 14, 454-461. [CrossRef]

44. Jiang, W.C.; Zhang, H.; Xu, Y.; Jiang, C.; Xu, Y.; Liu, W.; Tan, Y. Cutaneous vessel features of sensitive skin and its underlying functions. Ski. Res. Technol. 2020, 26, 431-437. [CrossRef]

45. Richters, R.; Falcone, D.; Uzunbajakava, N.; Verkruysse, W.; van Erp, P.; van de Kerkhof, P. What Is Sensitive Skin? A Systematic Literature Review of Objective Measurements. Ski. Pharm. Physiol. 2014, 28, 75-83. [CrossRef]

46. Kim, Y.R.; Cheon, H.I.; Misery, L.; Taieb, C.; Lee, Y.W. Sensitive skin in Korean population: An epidemiological approach. Ski. Res. Technol. 2018, 24, 229-234. [CrossRef]

47. Misery, L.; Ezzedine, K.; Corgibet, F.; Dupin, N.; Sei, J.; Philippe, C.; Joly, P.; Taieb, C.; Richard, M. Sex- and age-adjusted prevalence estimates of skin types and unpleasant skin sensations and their consequences on quality of life: Results of a study of a large representative sample of the French population. Br. J. Dermatol. 2019, 180, 1549-1550. [CrossRef]

48. Berardesca, E.; Maibach, H.I. Racial differences in sodium lauryl sulphate induced cutaneous irritation: Black and white. Contact Dermat. 1988, 18, 65-70. [CrossRef]

49. Löffler, H.; Pirker, C.; Aramaki, J.; Frosch, P.J.; Happle, R.; Effendy, I. Evaluation of skin susceptibility to irritancy by routine patch testing with sodium lauryl sulfate. Eur. J. Dermatol. 2001, 11, 416-419.

50. Farage, M.A. Perceptions of Sensitive Skin with Age. In Textbook of Aging Skin; Farage, M.A., Miller, K.W., Maibach, H.I., Eds.; Springer: Berlin/Heidelberg, Germany, 2010; pp. 1027-1046.

51. Misery, L.; Jourdan, E.; Huet, F.; Brenaut, E.; Cadars, B.; Virassamynaïk, S.; Sayag, M.; Taieb, C. Sensitive skin in France: A study on prevalence, relationship with age and skin type and impact on quality of life. J. Eur. Acad. Dermatol. Venereol. 2018, 32, 791-795. [CrossRef]

52. Farage, M.A. Perceptions of Sensitive Skin with Age. In Textbook of Aging Skin, 2nd ed.; Farage, M.A., Miller, K.W., Maibach, H.I., Eds.; Springer: Berlin/Heidelberg, Germany, 2017.

53. Farage, M.A. Perceptions of sensitive skin: Women with urinary incontinence. Arch. Gynecol. Obstet. 2009, 280, 49-57. [CrossRef]

54. Farage, M. Self-reported immunological and familial links in individuals who perceive they have sensitive skin. Br. J. Dermatol. 2008, 159, 237-238. [CrossRef]

55. Farage, M.A.; Jiang, Y.; Tiesman, J.P.; Fontanillas, P.; Osborne, R. Genome-Wide Association Study Identifies Loci Associated with Sensitive Skin. Cosmetics 2020, 7, 49. [CrossRef]

56. Bataille, A.; Le Gall-Ianotto, C.; Genin, E.; Misery, L. Sensitive Skin: Lessons from Transcriptomic Studies. Front. Med. 2019, 6, 115. [CrossRef]

57. Misery, L.; Sibaud, V.; Merial-Kieny, C.; Taieb, C. Sensitive skin in the American population: Prevalence, clinical data, and role of the dermatologist. Int. J. Dermatol. 2011, 50, 961-967. [CrossRef]

58. Jourdain, R.; De Lacharrière, O.; Bastien, P.; Maibach, H.I. Ethnic variations in self-perceived sensitive skin: Epidemiological survey. Contact Dermat. 2002, 46, 162-169. [CrossRef] 
59. Brenaut, E.; Misery, L.; Taieb, C. Sensitive Skin in the Indian Population: An Epidemiological Approach. Front. Med. 2019,6 , 29. [CrossRef]

60. Taieb, C.; Auges, M.; Georgescu, V.; Cullell, N.P.; Miséry, L. Sensitive skin in Brazil and Russia: An epidemiological and comparative approach. Eur. J. Dermatol. 2014, 24, 372-376. [CrossRef]

61. Farage, M.A.; Miller, K.W.; Zouboulis, C.C.; Piérard, G.E.; Maibach, H. Gender Differences in Skin Aging and the Changing Profile of the Sex Hormones with Age. J. Steroids Horm. Sci. 2012, 3, 109-124. [CrossRef]

62. Farage, M.A.; Neill, S.; MacLean, A.B. Physiological changes associated with the menstrual cycle: A review. Obstet. Gynecol. Surv. 2009, 64, 58-72. [CrossRef] [PubMed]

63. Shah, M.G.; Maibach, H.I. Estrogen and skin. An overview. Am. J. Clin. Dermatol. 2001, 2, 143-150. [CrossRef] [PubMed]

64. Farage, M.A.; Miller, K.W.; Berardesca, E.; Maibach, H.I. Sex Hormones, the skin and the immune system: Interactions and implications for skin testing. Sex Hormones, the skin and the immune system: Interactions and Treatment Strategies. Dermatology 2011, 1, 62-70.

65. Trowbridge, M.M.; Cheng, R.; Farage, M.A. The Association between Perception of Sensitive Skin and Objective and Subjective Measures in Women with Urinary Incontinence. Fam. Med. Med. Sci. Res. 2017, 6, 221. [CrossRef]

66. Besné, I.; Descombes, C.; Breton, L. Effect of age and anatomical site on density of sensory innervation in human epidermis. Arch. Dermatol. 2002, 138, 1445-1450. [CrossRef]

67. Xiao, X.; Qiao, L.; Ye, R.; Zuo, F. Nationwide Survey and Identification of Potential Stress Factor in Sensitive Skin of Chinese Women. Clin. Cosmet. Investig. Dermatol. 2020, 13, 867-874. [CrossRef]

68. Misery, L.; Taïeb, C.; Brenaut, E.; Huet, F.; Abasq-Thomas, C.; Sayag, M.; Bodemer, C. Sensitive Skin in Children. Acta Derm.Venereol. 2020, 100, adv00039. [CrossRef]

69. Hägglund, D.; Olsson, H.; Leppert, J. Urinary incontinence: An unexpected large problem among young females. Results from a population-based study. Fam. Pract. 1999, 16, 506-509. [CrossRef]

70. Jolleys, J.V. Reported prevalence of urinary incontinence in women in a general practice. Br. Med. J. Clin. Res. Ed. 1988, 296, 1300-1302. [CrossRef]

71. Thomas, T.M.; Plymat, K.R.; Blannin, J.; Meade, T.W. Prevalence of urinary incontinence. Br. Med. J. 1980, 281, 1243-1245. [CrossRef]

72. Kim, E.J.; Lee, D.H.; Kim, Y.K.; Kim, M.-K.; Kim, J.Y.; Lee, M.J.; Choi, W.W.; Eun, H.C.; Chung, J.H. Decreased ATP synthesis and lower pH may lead to abnormal muscle contraction and skin sensitivity in human skin. J. Dermatol. Sci. 2014, 76, $214-221$. [CrossRef]

73. Yang, L.; Lyu, L.; Wu, W.; Lei, D.; Tu, Y.; Xu, D.; Feng, J.; He, L. Genome-wide identification of long non-coding RNA and mRNA profiling using RNA sequencing in subjects with sensitive skin. Oncotarget 2017, 8, 114894-114910. [CrossRef] [PubMed]

74. Szymanski, M.; Barciszewska, M.Z.; Erdmann, V.A.; Barciszewski, J. A new frontier for molecular medicine: Noncoding RNAs. Biochim. Biophys. Acta 2005, 1756, 65-75. [CrossRef] [PubMed]

75. Farage, M.A. Perceptions of sensitive skin: Changes in perceived severity and associations with environmental causes. Contact Dermat. 2008, 59, 226-232. [CrossRef]

76. Brenaut, E.; Barnetche, T.; Le Gall-Ianotto, C.; Roudot, A.C.; Misery, L.; Ficheux, A. Triggering factors in sensitive skin from the worldwide patients' point of view: A systematic literature review and meta-analysis. J. Eur. Acad. Dermatol. Venereol. 2019, 34, 230-238. [CrossRef]

77. Xiong, X.-J.; Meng, X.-J.; Zheng, T.-L. Biosorption of C.I. Direct Blue 199 from aqueous solution by nonviable Aspergillus niger. J. Hazard. Mater. 2010, 175, 241-246. [CrossRef]

78. Farage, M.A.; Miller, K.W.; Wippel, A.M.; Berardesca, E.; Misery, L. Sensitive Skin in the United States: Survey of Regional Differences. Fam. Med. Med. Sci. Res. 2013, 2,1-8.

79. Kluger, N.; Le Floc'h, C.; Niore, M.; Delvigne, V.; Le Dantec, G.; Taieb, C. Self-Reported Skin Sensation by People Who Have Experienced Containment During COVID-19 Pandemic. Clin. Cosmet. Investig. Dermatol. 2020, 13, 943-947. [CrossRef]

80. Farage, M.A. Does sensitive skin differ between men and women? Cutan. Ocul. Toxicol. 2010, 29, 153-163. [CrossRef]

81. Farage, M.A. Perceptions of Sensitive Skin of the Genital Area. In Topical Applications and the Mucosa; Surber, C., Elsner, P., Farage, M.A., Eds.; Karger: Basel, Switzerland, 2011; pp. 142-154.

82. Farage, M.A.; Bowtell, P.; Katsarou, A. Self-diagnosed sensitive skin in women with clinically diagnosed atopic dermatitis. Clin. Med. Dermatol. 2008, 2, 21-28.

83. Mikkelsen, C.S.; Holmgren, H.R.; Kjellman, P.; Heidenheim, M.; Karppinnen, A.; Bjerring, P.; Huldt-Nystrøm, T. Rosacea: A clinical review. Dermatol. Rep. 2016, 8, 6387. [CrossRef]

84. Wang, X.Y.; Liu, Y.Y.; Liu, Y.X.; Ma, W.W.; Zhang, J.W.; Liu, Z.J.; Liu, J.; Zhou, B.R.; Xu, Y. A predictive model for differential diagnosis between rosacea and sensitive skin: A cross-sectional study. Chin. Med. J. Engl. 2020, 133, 2132-2134. [CrossRef] [PubMed]

85. Misery, L.; Duboc, H.; Coffin, B.; Brenaut, E.; Huet, F.; Taieb, C. Association between two painful and poorly understood conditions: Irritable bowel and sensitive skin syndromes. Eur. J. Pain 2019, 23, 160-166. [CrossRef] [PubMed]

86. Halioua, B.; Misery, L.; Seite, S.; Delvigne, V.; Chelli, C.; Taieb, J.; Taieb, C. Influence of Skin Subjective Symptoms on Sleep Quality in Patients with Cutaneous Disorders: A Study of 2871 Subjects. Clin. Cosmet. Investig. Dermatol. 2021, 14, 143-152. [CrossRef] [PubMed] 
87. Chang, A.L.S.; Raber, I.; Xu, J.; Li, R.; Spitale, R.; Chen, J.; Kiefer, A.K.; Tian, C.; Eriksson, N.K.; Hinds, D.; et al. Assessment of the Genetic Basis of Rosacea by Genome-Wide Association Study. J. Investig. Dermatol. 2015, 135, 1548-1555. [CrossRef] [PubMed]

88. Thompson, W.G.; Longstreth, G.F.; Drossman, D.A.; Heaton, K.W.; Irvine, E.J.; Muller-Lissner, S.A. Functional bowel disorders and functional abdominal pain. Gut 1999, 45, II43-II47. [CrossRef] [PubMed]

89. Huet, F.; Misery, L. Sensitive skin is a neuropathic disorder. Exp. Dermatol. 2019, 28, 1470-1473. [CrossRef]

90. Mostaghimi, L.; Hetzel, S. Insomnia and other sleep complaints in inflammatory versus noninflammatory skin disorders: An observational case-control study. Int. J. Dermatol. 2019, 58, 976-981. [CrossRef]

91. Littlejohn, G.; Guymer, E. Neurogenic inflammation in fibromyalgia. Semin. Immunopathol. 2018, 40, 291-300. [CrossRef]

92. Huynh, T.T. Burden of Disease: The Psychosocial Impact of Rosacea on a Patient's Quality of Life. Am. Health Drug Benefits 2013, $6,348-354$.

93. Reich, A.; Wójcik-Maciejewicz, A.; Slominski, A.T. Stress and the skin. G. Ital. Dermatol. Venereol. 2010, 145, 213-219. [PubMed]

94. Blount, B.W.; Pelletier, A.L. Rosacea: A common, yet commonly overlooked, condition. Am. Fam. Physician 2002, 66, 435-440.

95. Misery, L.; Myon, E.; Martin, N.; Consoli, S.; Boussetta, S.; Nocera, T.; Taieb, C. Sensitive skin: Psychological effects and seasonal changes. J. Eur. Acad. Dermatol. Venereol. 2007, 21, 620-628. [CrossRef] [PubMed]

96. Misery, L.; Jean-Decoster, C.; Mery, S.; Georgescu, V.; Sibaud, V. A New Ten-Item Questionnaire for Assessing Sensitive Skin: The Sensitive Scale-10. Acta Derm.-Venereol. 2014, 94, 635-639. [CrossRef]

97. Finlay, A.Y.; Khan, G. Dermatology Life Quality Index (DLQI)-a simple practical measure for routine clinical use. Clin. Exp. Dermatol. 1994, 19, 210-216. [CrossRef]

98. Jenkinson, C.; Layte, R.; Jenkinson, D.; Lawrence, K.; Petersen, S.; Paice, C.; Stradling, J. A shorter form health survey: Can the SF-12 replicate results from the SF-36 in longitudinal studies. J. Public Health 1997, 19, 179-186. [CrossRef]

99. Misery, L.; Jourdan, E.; Abadie, S.; Ezzedine, K.; Brenaut, E.; Huet, F.; Sayag, M.; Taieb, C. Development and validation of a new tool to assess the Burden of Sensitive Skin (BoSS). J. Eur. Acad. Dermatol. Venereol. 2018, 32, 2217-2223. [CrossRef] [PubMed]

100. Misery, L.; Myon, E.; Martin, N.; Verriere, F.; Nocera, T.; Taieb, C. Sensitive skin in France: An epidemiological approach. Ann. Dermatol. Venereol. 2005, 132, 425-429. [CrossRef]

101. Fauger, A.; Lhoste, A.; Chavagnac-Bonneville, M.; Sayag, M.; Jourdan, E.; Ardiet, N.; Perichaud, C.; Trompezinski, S.; Misery, L. Effects of a new topical combination on sensitive skin. J. Cosmet. Sci. 2015, 66, 79-86. [PubMed]

102. Farage, M.A.; Nusair, T.L.; Hanseman, D.; Sherman, S.N.; Tsevat, J. The Farage Quality of Life Measure for Consumer Products: Development and Initial Implementation. Appl. Res. Qual. Life 2010, 5, 1-25. [CrossRef]

103. Zhang, L.; Adique, A.; Sarkar, P.; Shenai, V.; Sampath, M.; Lai, R.; Qi, J.; Wang, M.; Farage, M.A. The Impact of Routine Skin Care on the Quality of Life. Cosmetics 2020, 7, 59. [CrossRef] 